\title{
What is the level of evidence for the use of currently available technologies in facilitating the self-management of difficulties associated with ADHD in children and young people? A systematic review
}

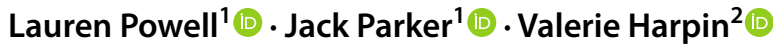

Received: 4 July 2017 / Accepted: 27 November 2017 / Published online: 8 December 2017

(c) The Author(s) 2017. This article is an open access publication

\begin{abstract}
A number of technologies to help self-manage attention deficit hyperactivity disorder (ADHD) in children and young people (YP) have been developed. This review will assess the level of evidence for the use of such technologies. The review was undertaken in accordance with the general principles recommended in the Preferred Reporting Items for Systematic Reviews and Meta-Analysis. 7545 studies were screened. Fourteen studies of technology that aim to self-manage difficulties associated with ADHD in children and YP were included. Primary outcome measures were measures that assessed difficulties related to ADHD. Databases searched were MEDLINE, Web of Science (Core collection), CINAHL, the Cochrane Library, ProQuest ASSIA, PsycINFO and Scopus. The methodological quality of the studies was assessed. This review highlights the potential for the use of technology in paediatric ADHD management. However, it also demonstrates that current research lacks robustness; using small sample sizes, non-validated outcome measures and little psychoeducation component. Future research is required to investigate the value of technology in supporting children and YP with ADHD and a focus psychoeducation is needed.
\end{abstract}

Keywords Technology $\cdot$ Intervention $\cdot$ ADHD $\cdot$ Psychoeducation

\begin{tabular}{|c|c|c|c|}
\hline \multicolumn{2}{|c|}{ Abbreviations } & ITT & Intention to treat \\
\hline \multirow{4}{*}{$\begin{array}{l}\text { ADHD } \\
\text { ADHD-RS } \\
\text { AVL } \\
\text { BRIEF }\end{array}$} & Attention deficit hyperactivity disorder & MABC-2-NL & Movement assessment battery for children \\
\hline & ADHD Rating Scale & MCID & Minimally clinically important difference \\
\hline & ADHD vragen lijst & MeSH & Medical subject headings \\
\hline & Behaviour rating inventory of executive & SDQ & Strengths and difficulties questionnaire \\
\hline & $\begin{array}{l}\text { function } \\
\text { Corsi block tapping task }\end{array}$ & SPRSQ-C & $\begin{array}{l}\text { Sensitivity to punishment and sensitivity } \\
\text { to reward questionnaire for children }\end{array}$ \\
\hline CPT & Conners continuous performance test & SRRS & Social skills rating system \\
\hline CRoB & Cochrane risk of bias & TMT & Trail making test \\
\hline \multirow[t]{2}{*}{ DBDRS } & Disruptive Behaviour Disorder Rating & TMQ & Time management questionnaire \\
\hline & Scale & RCT & Randomised controlled trial \\
\hline D-KEFS & Delis-Kaplan function system & SAST & South Australian spelling test \\
\hline HSQ & Home situations questionnaire & QbTest & Quantifying behaviour test \\
\hline IATQ & It is about time questionnaire & WAIS-RNI & $\begin{array}{l}\text { Weschler adult intelligence scale-revised } \\
\text { as a neuropsychological instrument }\end{array}$ \\
\hline \multicolumn{2}{|c|}{$\begin{array}{l}\square \text { Lauren Powell } \\
\text { L.A.Powell@Sheffield.ac.uk }\end{array}$} & $\begin{array}{l}\text { WASI } \\
\text { WISC-III }\end{array}$ & $\begin{array}{l}\text { Weschler abbreviated scale of intelligence } \\
\text { Weshler intelligence scale for children } \\
\text { three }\end{array}$ \\
\hline \multicolumn{2}{|c|}{$\begin{array}{l}\text { School of Health and Related Research, Regent Court, } 30 \\
\text { Regent Street, Sheffield S1 4DA, UK }\end{array}$} & WPPSI-RN & $\begin{array}{l}\text { Wechsler preschool and primary scale of } \\
\text { intelligence revised }\end{array}$ \\
\hline \multicolumn{2}{|l|}{2} & YP & Young people \\
\hline
\end{tabular}




\section{Introduction}

Attention deficit hyperactivity disorder (ADHD) is a highly comorbid [1-3] neurodevelopmental disorder. It has a worldwide prevalence of 3-5\% in school age children [4], 80-85\% of these individuals continue to be effected by their ADHD into adolescence [5-8] and 60\% into adulthood [9].

Due to the symptoms and complexity of the condition, there are a number of important long-term difficulties associated with ADHD. These include low academic attainment $[10,11]$, which can persist into adulthood [12], poor executive functioning [13], poor social relationships, strained parent/child/sibling relationships [14] and problems with social interactions with peers [15]. This results in poorer quality of life and self-esteem in children and YP with ADHD $[16,17]$.

Children and YP with ADHD are reliant on clinicians and parents to help them to manage their condition. However, as they transit into adulthood, the support is not as readily available or indeed wanted by the individual [18]. It is, therefore, imperative that children and YP learn to self-manage their condition and indeed be educated about their condition and how to manage it [19-23]. Individuals with ADHD often experience crises and access to their usual services may not be immediately available. However, the increasing sophistication and usage of technology may provide valuable resources to facilitate the self-management of ADHD for children and YP.

Over recent years, technological advances have meant that technology is more widely available and has become more popular and integrated into many lives. Society is also better connected with an estimated $46 \%$ of the worldwide population having an internet connection compared with $1 \%$ in 1995 [24]. As a result of this, a number of attempts have been made to harness technology to help manage ADHD in children and YP such as eye tracking [25], brain computer interface $[26,27]$ and a computerised test that quantifies ADHD core symptoms; the QbTest [28]. Technology has also been used for cognitive training in children and YP with ADHD [29]. However, these technologies are reliant on an administrator or a therapist. Other technologies have been developed to self-manage ADHD-related difficulties in children and YP that can be used independently of a therapist which, therefore, reduces the reliance on services. These include a handheld organisation device [30], a device to self-monitor ADHD symptoms [31], computer software to improve reading speed [32], and computer games that focus on mathematical ability [33] and the promotion of behavoural learning and organisation [34]. Although these studies report that technology has the potential to self-manage ADHD-related difficulties in children and YP, little is known about the level of evidence for these technologies. Therefore, this review will assess the level of evidence for currently available technologies for self-managing ADHD and related difficulties in children and YP.

\section{Methods}

The review protocol was registered with PROSPERO (CRD42017057715). The review was undertaken in accordance with the general principles recommended in the Preferred Reporting Items for Systematic Reviews and MetaAnalysis [35].

\section{Search methods}

The following databases were searched in February 2017 from the last 5 years: MEDLINE, Web of Science (Core collection), CINAHL, the Cochrane Library, ProQuest ASSIA, PsycINFO and Scopus. Medical Subject Headings (MeSH) keywords used were attention deficit disorder with hyperactivity, hyperkinesis, attention deficit and disruptive behaviour disorders, conduct disorder, child behaviour disorders, disruptive impulse control and conduct disorders, adolescent, young adult, educational technology, technology, self-help devices, video games, internet, software, social media, mobile applications, self care and social support. Text terms used were attention deficit and disruptive behaviour disorders, attention deficit hyperactivity disorder, ADHD, ADDH, ADHS, hkd, attention, behaviour, dysfunctional, disorder, disrupt, defiant, impulsive, inattentive, inattention, hyperkinesis, damage, hyperactive, conduct, child, boy, girl, young person, YP, young people, adolescent, teen, youth, technology, assistive technology, self-help devices, game, website, download, forum, email, mobile app, condition management, manage, self-manage, support and support network. Terms were combined using Boolean logic ("AND", "OR"). MeSH is specific recognised terms used for the purpose of identifying journal articles and books in electronic databases. Free text terms and synonyms are specific words that the search strategy looks for in the title and abstract.

A copy of the MEDLINE search strategy is presented in Appendix 1. Electronic citations were downloaded to Endnote software. The inclusion criteria are described in Table 1. Studies included in this review were from 2014 to 2016.

Due to the infancy of this research topic, any study design was accepted as appropriate to answer the research question. The research question is "What is the level of evidence that current technology that aims to self-manage difficulties associated with ADHD in children and young people is helpful?" The primary outcome measures (see Table 2) of this review are measures that assess ADHD related difficulties. 
Table 1 Inclusion and exclusion criteria for this review

\begin{tabular}{ll}
\hline Inclusion criteria & Exclusion criteria \\
\hline English language articles & Studies where intervention is not clearly defined \\
Studies recruiting individuals under the age of 18 years & Studies including individuals over the age of 18 years \\
Evaluating technologies that can be used independently of a therapist & Non-interventional studies \\
Participants reported to have ADHD diagnosis & Interventions that are led by anybody other than the child/YP with \\
& ADHD (e.g. clinician led interventions) \\
& $\begin{array}{c}\text { Participants without reported ADHD diagnosis (e.g. parent or teacher } \\
\text { Validated outcome measures assessing ADHD-related difficulties }\end{array}$ \\
& Outcome measures that do not assess ADHD-related difficulties or are \\
\end{tabular}

$A D H D$ attention deficit hyperactivity disorder

Table 2 List of included outcome measures

\begin{tabular}{|c|c|c|}
\hline $\begin{array}{l}\text { Observational checklist for observations and } \\
\text { recording behaviours }\end{array}$ & Conners parent scale (brief version) & Corsi Block Tapping Task (CBTT) \\
\hline $\begin{array}{l}\text { Chart to track each students appropriate } \\
\text { behaviour }\end{array}$ & Connors teacher rating scale & $\begin{array}{l}\text { Digit span subtest from the Weschler Intelli- } \\
\text { gence Scale for Children (WISC-III) }\end{array}$ \\
\hline Guided reading packet & $\begin{array}{l}5 \text { subtests from the Movement Assessment } \\
\text { Battery for Children (MABC-2-NL) }\end{array}$ & $\begin{array}{l}\text { Disruptive Behaviour Disorders Rating Scale } \\
\text { (DBDRS; parent and teacher versions) }\end{array}$ \\
\hline $\begin{array}{l}\mathrm{X} 2 \text { outcome measures-multiple choice, fill } \\
\text { in the blanks and short answer response }\end{array}$ & $\begin{array}{l}\text { Behaviour Rating Inventory of Executive } \\
\text { Function (BRIEF): plan/organise }\end{array}$ & $\begin{array}{l}\text { Sensitivity to punishment and sensitivity to } \\
\text { reward questionnaire for children (SPRSQ-C) }\end{array}$ \\
\hline Total time to complete reading & BRIEF: working memory subscale_-parent & $\begin{array}{l}\text { Paediatric quality of life inventory (PedsQL; } \\
\text { parent and child versions) }\end{array}$ \\
\hline Sustained attention dots task version $02 \mathrm{k}$ & Shape school & Counting span task \\
\hline Calculating time for distractions & BRIEF—inhibit & Connors Continuous Performance Test (CPT II) \\
\hline Time calculation & BRIEF-shift & WISC III \\
\hline Barkley School Situations Questionnaire & BRIEF-emotional & $\begin{array}{l}\text { Social Skills Rating Scale (SRRS) self-control } \\
\text { subscale }\end{array}$ \\
\hline Go/no-go task (not QbTest) & BRIEF-control initiate & SRRS total \\
\hline $\begin{array}{l}\text { Time management questionnaire-parent and } \\
\text { teacher completion }\end{array}$ & BRIEF—organisation of materials & ADHD VragenLijst (AVL) \\
\hline $\begin{array}{l}\text { It's About time Questionnaire (IATQ)—parent } \\
\text { version }\end{array}$ & BRIEF-monitor & SSRS—teacher version \\
\hline Self efficacy questionnaire & BRIEF-metacognition index & Stop task \\
\hline Knox cubes LDT & $\begin{array}{l}\text { Weshler Preschool and Primary Scale of } \\
\text { Intelligence Revised translated in Dutch } \\
\text { (WPPSI-R NL) }\end{array}$ & ADHD Rating Scale 1 (ADHD-RS-1) \\
\hline Action detector & $\begin{array}{l}\text { Subscale of Cooperation of the SRRS (parent } \\
\text { version) }\end{array}$ & Stroop (and day/night version) \\
\hline Duration of arbitrary standing & SRRS: subscales Responsibility & The home situations questionnaire (HSQ) \\
\hline $\begin{array}{l}\text { Disruptive Behaviour Disorder Rating Scale } \\
\text { (DBDRS) }\end{array}$ & SRRS: assertiveness subscale & $\begin{array}{l}\text { Raven coloured progressive matrices (full and } \\
\text { shortened version) }\end{array}$ \\
\hline Improvement index during training & $\begin{array}{l}\text { Three subtests in Mandarin Literacy Assess- } \\
\text { ment }\end{array}$ & ADHD Rating Scale (ARS-IV) \\
\hline $\begin{array}{l}\text { Strengths and Difficulties Questionnaire } \\
\text { (SDQ) }\end{array}$ & $\begin{array}{l}\text { Trail Making Test (TMT) of the Delis-Kaplan } \\
\text { Function System (D-KEFS) }\end{array}$ & $\begin{array}{l}\text { Weshler Abbreviated Scale of Intelligence } \\
\text { (WASI) }\end{array}$ \\
\hline South Australian Spelling Test (SAST) & & \\
\hline
\end{tabular}

\section{Quality Assessment}

Methodological quality of included studies was assessed using the Cochrane Risk of Bias tool (CRoB) [36] for RCT designs and the Downs and Black Instrument [37] for nonRCT designs. This CRoB tool addresses specific domains, namely, sequence generation, allocation concealment, blinding of participants and personnel, blinding of outcome 
assessment, incomplete outcome data, and selective outcome reporting. The Downs and Black Instrument provides an individual score for each study with a maximum score of 32 [37] and assesses the way in which the studies report their findings, external validity, internal validity bias and selection bias.

\section{Data extraction}

Retrieved titles, abstracts, and/or papers were screened independently by 2 review authors (LP, JP) to identify studies that met the inclusion criteria. Disagreements were resolved between reviewers through discussion. A standardised form was used for data extraction using Microsoft Excel. Details of the study characteristics, including participants, the intervention, and comparator (where applicable) were recorded. Data extraction was carried out by reviewer LP and checked for accuracy by reviewer JP.

\section{Outcome measurement assessment}

It is vital that when undertaking a systematic review, the quality of the outcome measures used in each of the included studies is assessed. This is to ensure the validity and reliability of their results. To complete the outcome measure quality assessment, where possible, three domains should be considered for each outcome measure [38], (1) whether the psychometric properties of the scale have been assessed previously [39], (2) whether the clinimetric properties of the outcome measure have been thought through [40-44], specifically the Minimally Clinically Important Difference (MCID) [43], and (3) whether the design and analysis of the outcome measure satisfies the requirements of measurement theory [45-47]. We identified all outcome measures $(N=58)$ used across the 14 studies and reviewed each of them individually to assess whether they fulfilled the first domain described above. The MCID was not assessed for the included outcome measures and was, therefore, not assessed. The 58 included outcome measures are listed in Table 2.

Literature for each outcome measure, where applicable, was reviewed. We then examined each outcome measure to ascertain how the data were scored, collected and analysed within the results section of each study.

In line with the literature, all 58 outcome measures included were measures of difficulties related to ADHD.

\section{Data synthesis}

We have presented a narrative overview of the included studies with supporting evidence tables and text. A meta-analysis was not undertaken.

\section{Appraisal of evidence}

The results of the search varied from case studies to Randomised Controlled Trials (RCTs). The studies identified were appraised using the levels of evidence [48] to locate the best available evidence that involves the application of systematic, robust, transparent and explicit methodology [49]. The grading system (see Table 3 ) was created to highlight that varying study designs and methodologies are at risk of bias in their results. This is crucial as the study design may affect the validity and reliability of results due to the research method used. For example, when evaluating the effectiveness of an intervention, it is often considered that RCT evidence is the "gold standard", the most reliable form of evidence due to the measures they take to reduce the influence confounding variables could potentially have on the results [50].

Table 3 Levels of evidence outlined by Weiss et al. [48]

\begin{tabular}{|c|c|c|c|c|}
\hline $\begin{array}{l}\text { Level of } \\
\text { evidence }\end{array}$ & Non-empirical & Group research & Outcome research & Single participant research \\
\hline I & - & Randomised controlled trial & - & $\mathrm{N}$-or-1 randomised controlled trial \\
\hline II & - & $\begin{array}{l}\text { Non-randomised control trial } \\
\text { Prospective cohort study with concurrent control } \\
\text { group }\end{array}$ & Analytic survey & $\begin{array}{l}\text { ABABA design } \\
\text { Alternating treatments. Multiple } \\
\text { baseline across participants }\end{array}$ \\
\hline III & - & $\begin{array}{l}\text { Case-control study. Cohort study with historical } \\
\text { control group }\end{array}$ & - & ABA design \\
\hline IV & & Before and after case series without control group & - & $\mathrm{AB}$ design \\
\hline V & $\begin{array}{l}\text { Descriptive case series } \\
\text { Anecdotes } \\
\text { Expert opinion } \\
\text { Theories } \\
\text { Common sense }\end{array}$ & & - & - \\
\hline
\end{tabular}




\section{Results}

\section{Search results}

The electronic searches identified 7391 citations following de-duplication, including 9 additional citations that were identified through reference searches/other sources. We excluded 7331 citations at the title and abstract stages as they did not fit the inclusion criteria. We then obtained 60 citations as full-text articles. Of these, 50 were excluded at the full-text stage; details of these excluded studies with the reason for exclusion are shown in Appendix 2. 14 studies reported across 14 publications were included in the review (see Fig. 1). Four of these publications were obtained from a recent meta analysis [29], which examined the effects of cognitive training on ADHD symptoms, neuropsychological deficits, and academic skills in children and YP with ADHD [51-54].

\section{Quality assessment}

Full details from the Cochrane risk of bias assessment are presented in Appendix 3. A summary of the RCT risk of bias assessment is presented in Table 4, non-RCT risk assessment

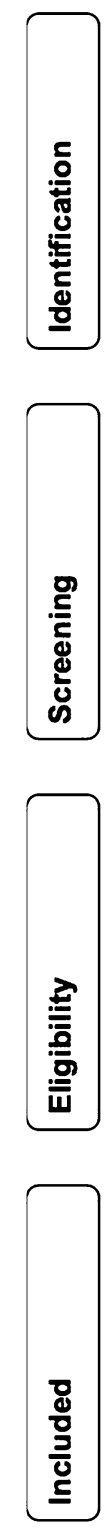

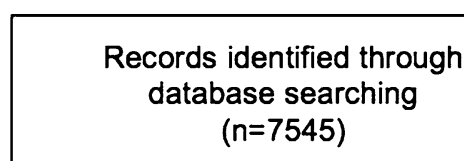

$(n=7545)$

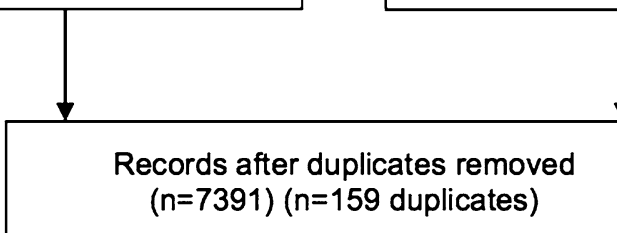

Additional records identified through other sources

$(n=9)$
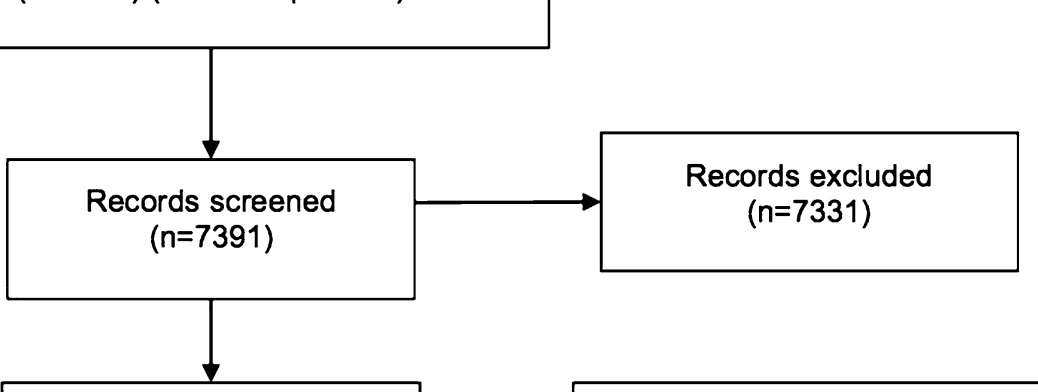

Full-text articles assessed for eligibility $(n=60)$
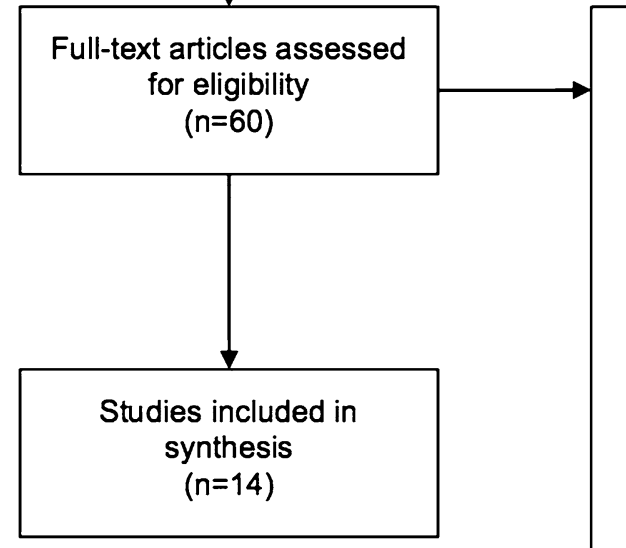

Full-text articles excluded, with reasons $(n=50)$

- Participants not diagnosed with ADHD

- Study not interventional

- Study intervention not technology

- Doesn't assess ADHD related difficulties

- Intervention reliant on health care professionals

- Participants ADHD not primary diagnosis

- Technology as outcome measure, not intervention

See appendices 2 for full break down of excluded full texts

Fig. 1 Studies included in this review 
Table 4 RCT risk of bias summary

\begin{tabular}{|l|l|l|l|l|l|l|}
\hline & & & & & \\
Study & $\begin{array}{l}\text { Random } \\
\text { Sequence } \\
\text { Generation }\end{array}$ & $\begin{array}{l}\text { Allocation } \\
\text { Concealment }\end{array}$ & $\begin{array}{l}\text { Blinding of } \\
\text { Participants and } \\
\text { Personnel }\end{array}$ & $\begin{array}{l}\text { Blinding of } \\
\text { Outcome } \\
\text { Assessment }\end{array}$ & $\begin{array}{l}\text { Incomplete } \\
\text { Outcome Data }\end{array}$ & $\begin{array}{l}\text { Selective } \\
\text { Reporting }\end{array}$ \\
\hline Bul, 2016 [34] & Low risk & Low risk & High Risk & High Risk & High Risk & Low risk \\
\hline $\begin{array}{l}\text { Van der Oord, 2014 } \\
{[57]}\end{array}$ & Low risk & Unclear & Unclear & Unclear & Low risk & Low risk \\
\hline Dovis, 2015[55] & Low risk & Low risk & Low risk & Low risk & Low risk & Low risk \\
\hline $\begin{array}{l}\text { Weerdemeester, 2016 } \\
{[56]}\end{array}$ & Low risk & Low risk & High Risk & Low risk & Low risk & Low risk \\
\hline $\begin{array}{l}\text { Van Dongen-Boomsma } \\
{[51]}\end{array}$ & Unclear & Low risk & Low risk & Low risk & Low risk & Low risk \\
\hline Egeland, 2013 [52] & Unclear & Low risk & High risk & High risk & Low risk & Low risk \\
\hline Klingberg, 2005 [54] & Unclear & Unclear & Low risk & Low risk & High risk & Low risk \\
\hline Johnstone, 2012 [53] & Unclear & Unclear & Unclear & Unclear & Unclear & Low risk \\
\hline
\end{tabular}

in Table 5 and a summary of the outcome measurement quality assessment can be found in Appendix 5.

One of the eight included RCTs, one was considered to be at overall high risk of bias [34], five RCTs were judged as being at overall low risk $[51,52,54,55,56]$ and two RCTs were considered to be at overall unclear risk of bias [53, 57]. All included RCTs were considered to be at a low risk of bias for selective reporting [34, 51-57].

Non-RCT study designs were assessed using the Downs and Black Scale, as they were mainly exploratory interventional studies. Overall, the non-RCT studies obtained low scores on items covering external and internal validity, selection bias and statistical power. Studies obtained higher scores for the items covering reporting of results and study procedures. The maximum total score that could be obtained is 32. Of the six included non-RCT studies in this review, the lowest score was 6 [58] and the highest score was 11 $[59,60]$.

\section{Quality assessment of measurement scales}

Ten of the fourteen included studies [34, 51-58, 63] used ordinal scales of measurement all with established psychometric properties. Twelve of the included studies [34, 51, 53-62] used scales of measurement that did not have established psychometric properties. Four of the fourteen studies [58-60, 63] did not perform any formal statistical analysis. The sample size for these four studies ranged from one to eight. Five of the fourteen studies [34, 52, 53, 56, 57] aggregated data used with ordinal scales, which may put findings at risk. Further details of the outcome measurement quality assessment can be found in Appendix 5. Description of the studies can be found in Table 6 .

\section{Discussion}

This review set out to answer the question "What is the level of evidence that current technology that aims to self-manage difficulties associated with ADHD in children and young people is helpful?" The review found that the evidence demonstrates that technology shows promise in self-managing difficulties related to ADHD in children and YP. However, this claim is based on evidence that often consists of small sample sizes, use a wide variety of outcome measures (many of which are not validated) and provide little support for the importance of the role of psychoeducation in children and YP with ADHD that has been so widely reported and encouraged elsewhere [19-23, 64]. For example, the European Guidelines suggest psychoeducation for parent/carer and child with ADHD as a first step to treatment [23]. One systematic review even stated that psychoeducation for YP with ADHD and their families could provide an expert understanding of their condition could lead to more positive individual choices [20].

Of the fourteen included studies in this review, the interventions assessed include two tablet devices [59, 60] two mobile applications $[58,62]$, the use of a Wii remote control [61], computer software [51, 54] and computer games [34, 52, 53, 55-57, 63]. Following exclusions, outcome measure assessment (Appendix 5) and quality assessment of the fourteen included studies was conducted (appendices 3 and 4).

Only four of the sixteen papers included in the Cortese et al. [29] meta analysis were included in this review [51-54] and one additional paper resulted from our search strategy before the Cortese review was screened for studies to include in this review [57]. Two of the unincluded papers presented in this meta analysis [29] did not report technological interventions $[65,66]$, one did not use validated outcome measures of ADHD-related difficulties [67], four reported 
Table 5 non-RCT risk of bias summary

\begin{tabular}{|c|c|c|c|c|c|c|}
\hline$\stackrel{\frac{\pi}{0}}{\ominus}$ & $=$ & $=$ & 6 & $a$ & $a$ & a \\
\hline$\hat{\imath}$ & 0 & 0 & 0 & 0 & 0 & 0 \\
\hline i & $\dot{0} \bar{z} \ll$ & $0^{\circ} \bar{Z} \ll$ & $0 \bar{z} \ll$ & $0 \bar{z} \ll$ & $0^{\circ} \bar{z} \ll$ & $0 \bar{z} \ll$ \\
\hline$\approx$ & 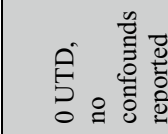 & 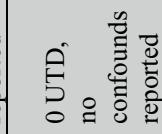 & 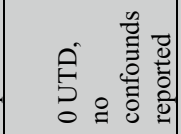 & 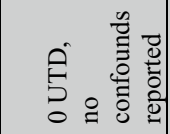 & 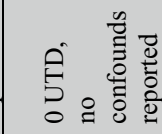 & 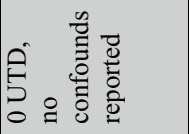 \\
\hline$\stackrel{ \pm}{\sim}$ & 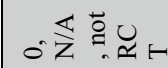 & 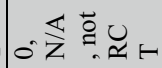 & 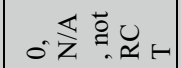 & 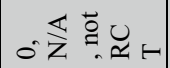 & 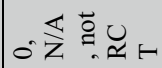 & 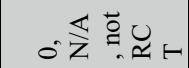 \\
\hline$\tilde{\imath}$ & 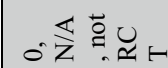 & 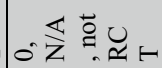 & 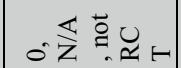 & 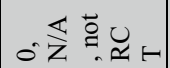 & 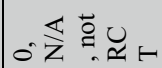 & 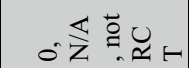 \\
\hline ส & - & - & - & - & - & - \\
\hline$\vec{\imath}$ & - & - & 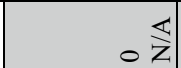 & 050 & $\circ 5$ & 0 \\
\hline ㄱ & 0 & 0 & - & 0 & 0 & - \\
\hline 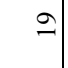 & - & - & - & - & 050 & $\circ 50$ \\
\hline$\infty$ & @ Е & 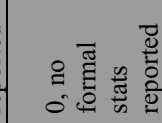 & 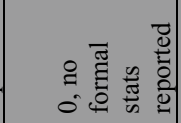 & 0 & 0 & @ हี \\
\hline$\Xi$ & - & - & 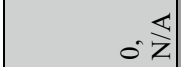 & 0 & - & - \\
\hline 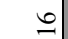 & 0 & 0 & 0 & 0 & 0 & 0 \\
\hline 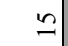 & 0 & 0 & 0 & 0 & 0 & 0 \\
\hline \pm & 0 & 0 & 0 & 0 & 0 & 0 \\
\hline$\underline{2}$ & - & - & $\circ 50$ & 050 & $\circ 50$ & \\
\hline$\simeq$ & 0 & 0 & 0 & 0 & 0 & 0 \\
\hline 二 & 0 & 0 & 0 & 0 & 0 & 0 \\
\hline 으 & 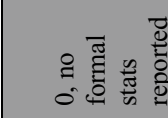 & ఏ & 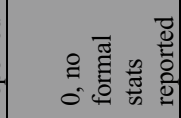 & $N$ & N & 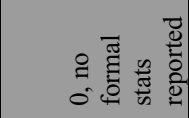 \\
\hline$a$ & $0 \bar{z} \ll$ & $0 \cdot \bar{z} \varangle$ & $0 \bar{z}<$ & $0 \bar{z}<$ & $0 \bar{z}<$ & $0 \bar{z} \ll$ \\
\hline$\infty$ & 0 & 0 & 0 & 0 & 0 & 0 \\
\hline$r$ & $0^{\circ} \bar{z} \varangle$ & $0 \hat{\mathbf{Z}} \ll$ & $0 \bar{z}<$ & óz & $0 \bar{z} \ll$ & $0 \cdot \bar{z} \ll$ \\
\hline 6 & $\sim$ & $N$ & - & $N$ & N & $N$ \\
\hline in & 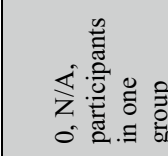 & 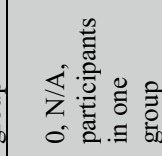 & 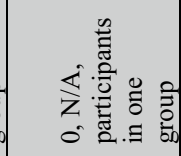 & 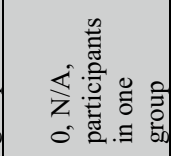 & 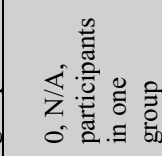 & 0 \\
\hline+ & - & 一 & 0 & - & 0 & - \\
\hline$m$ & - & - & - & - & - & - \\
\hline$N$ & - & - & - & - & - & - \\
\hline- & - & - & 0 & 0 & - & 0 \\
\hline & $\begin{array}{l}{[6 \mathrm{6S}]} \\
9 \mathrm{I} 0 \mathrm{r} \text { 'p.ojureg }\end{array}$ & {$\left[\begin{array}{l}{[09]} \\
\text { §I0Z 'vuu!d }\end{array}\right.$} & $\begin{array}{l}{[8 s]} \\
\text { tI } 0 z^{\prime} \text { ’nb!̣ueW } \\
\text {-z!ny }\end{array}$ & 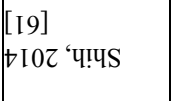 & [z9] 9ा0z 'u! ] & [ع9] ৎI0Z 'o[!y \\
\hline
\end{tabular}

*Item modified (see Appendix 4 for further details) 


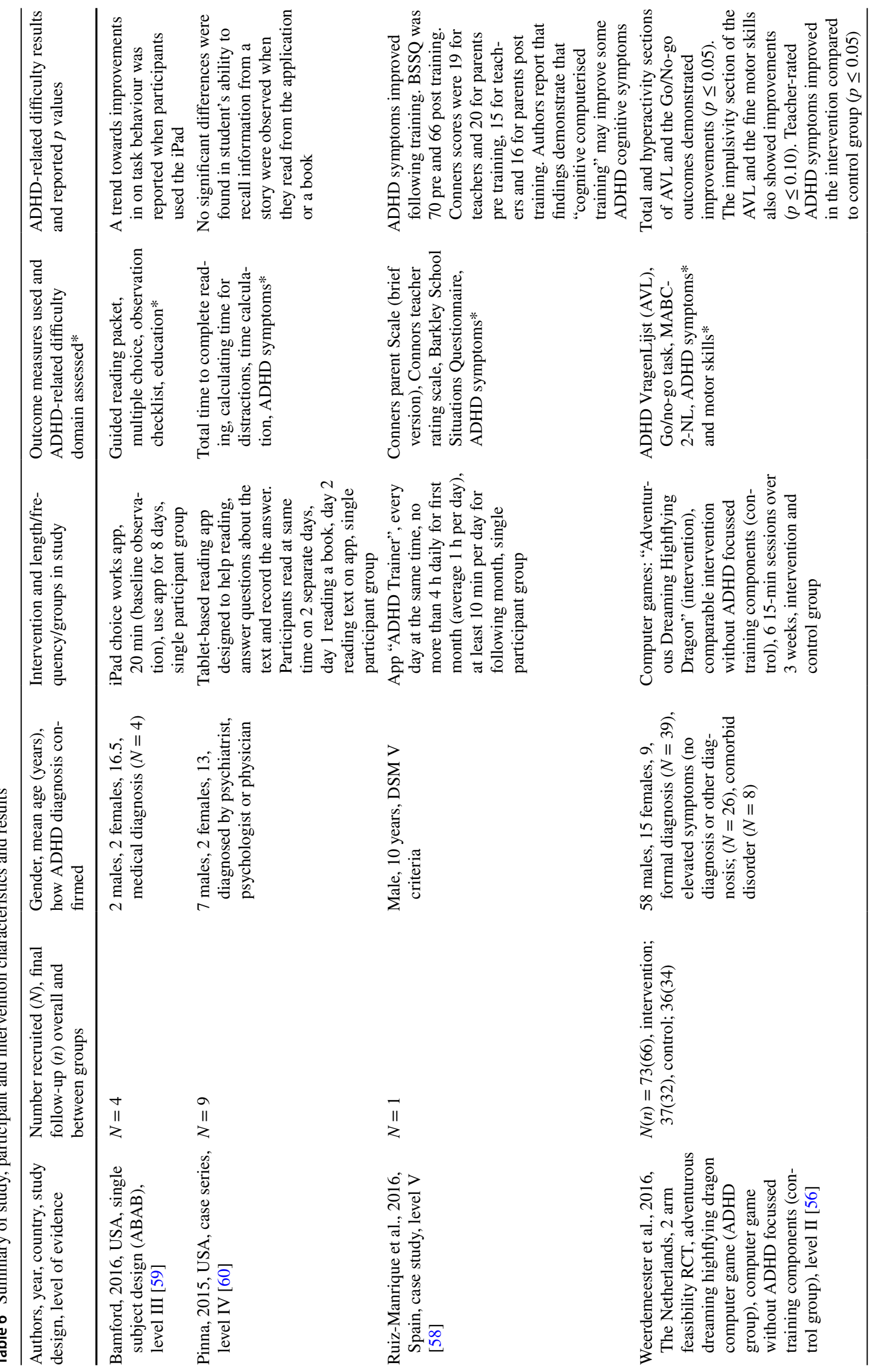




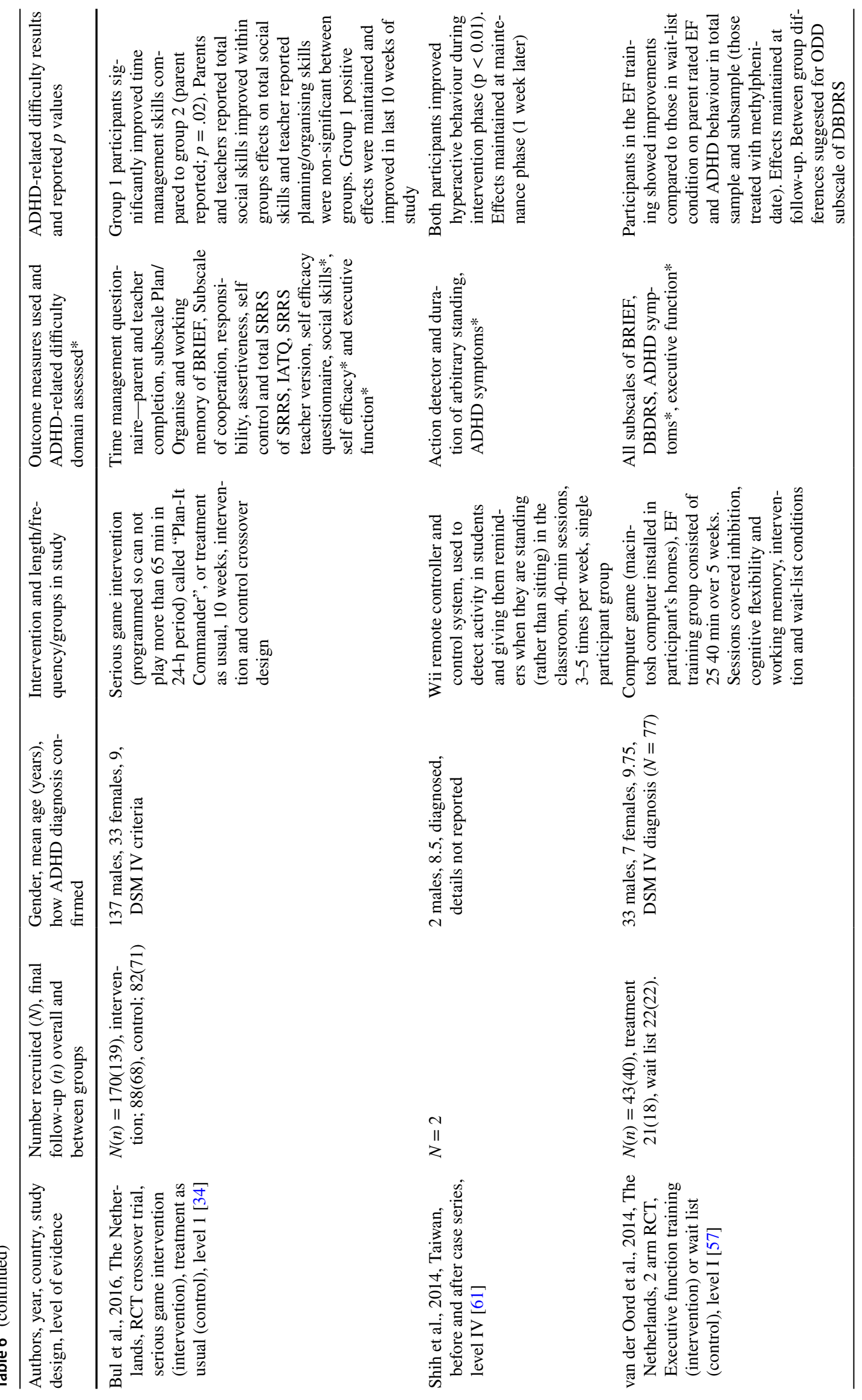




\begin{tabular}{|c|c|c|c|c|}
\hline 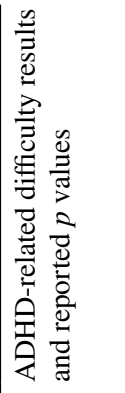 & 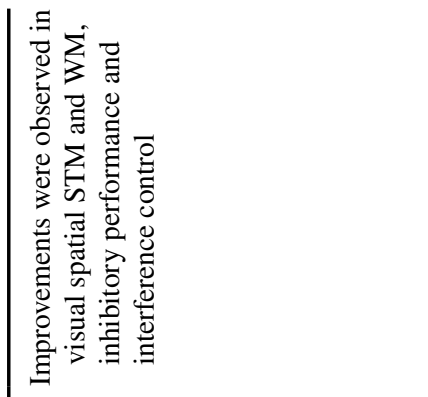 & 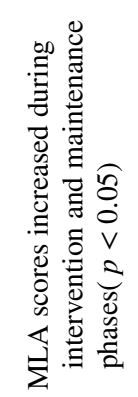 & 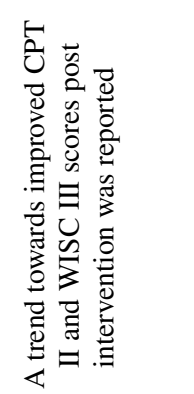 & 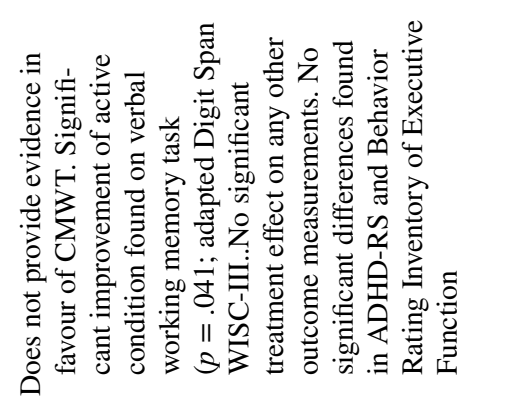 \\
\hline 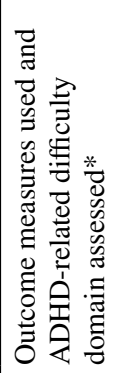 & 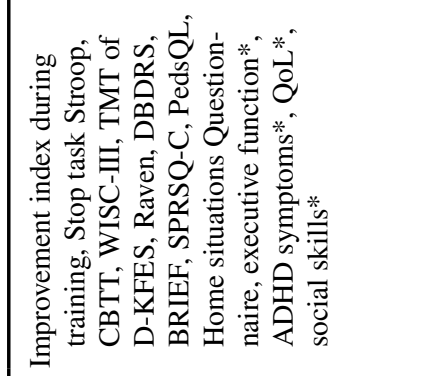 & 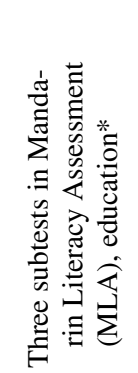 & 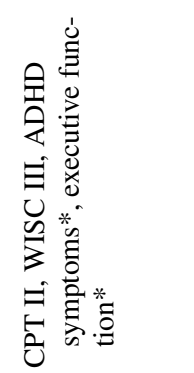 & 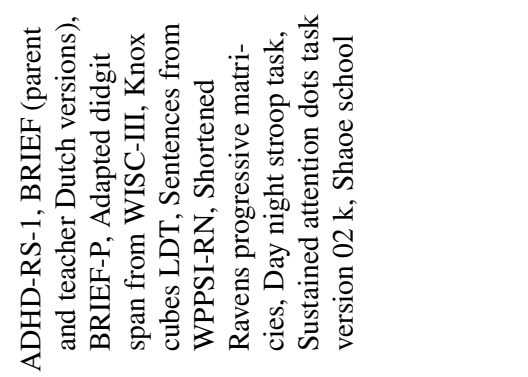 \\
\hline 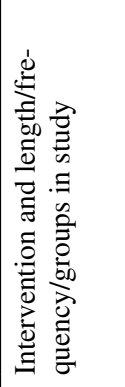 & 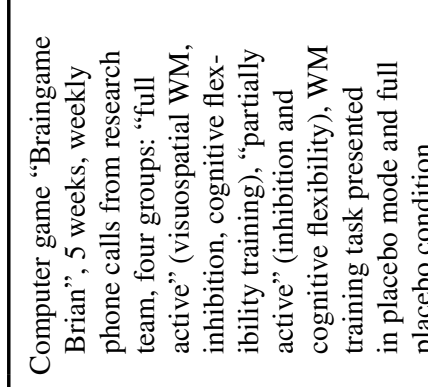 & 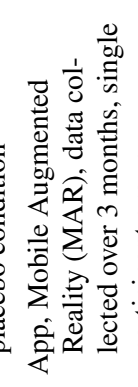 & 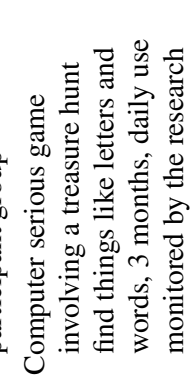 & 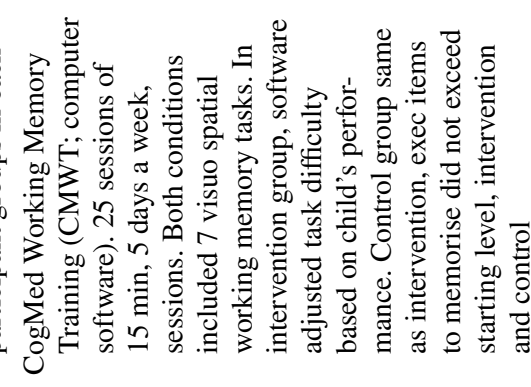 \\
\hline 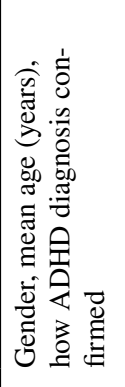 & 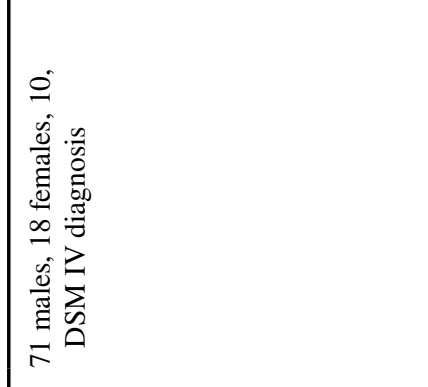 & 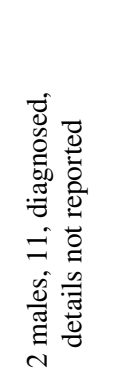 & 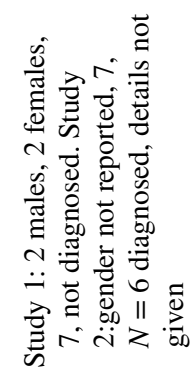 & 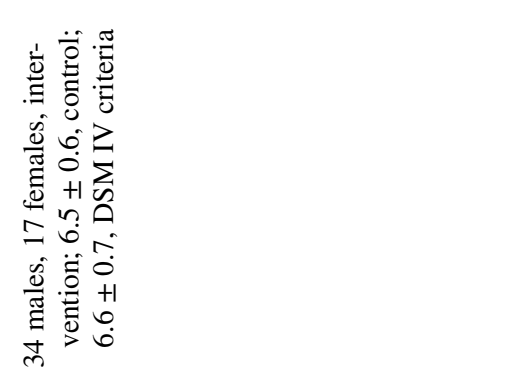 \\
\hline 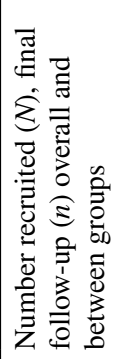 & 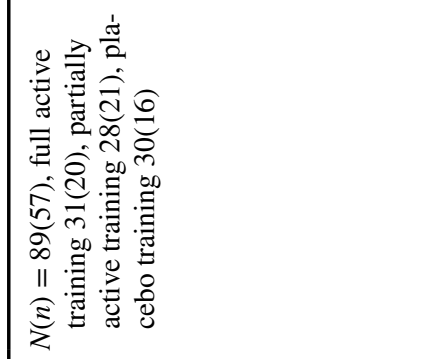 & $\begin{array}{l}N \\
\text { II }\end{array}$ & 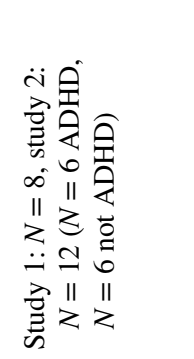 & 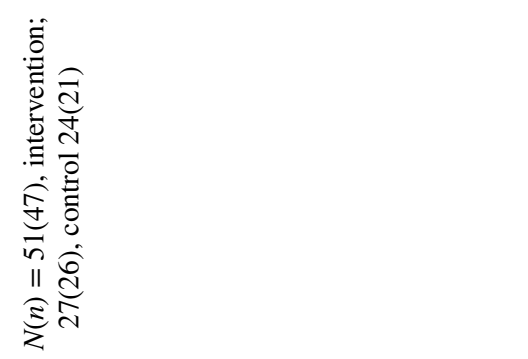 \\
\hline 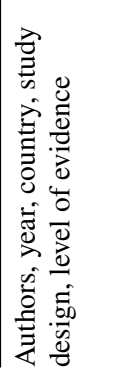 & 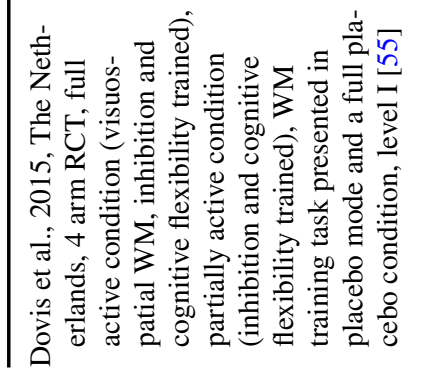 & 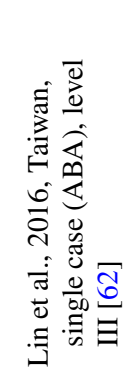 & 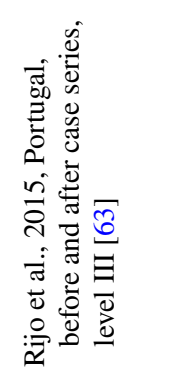 & 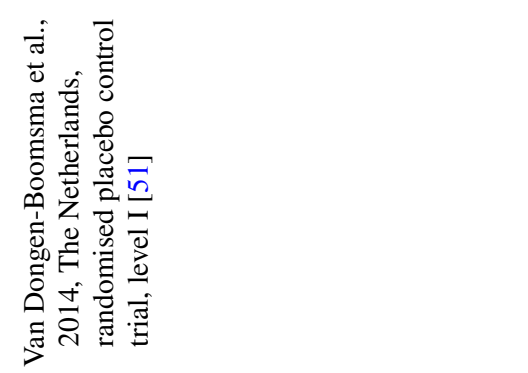 \\
\hline
\end{tabular}




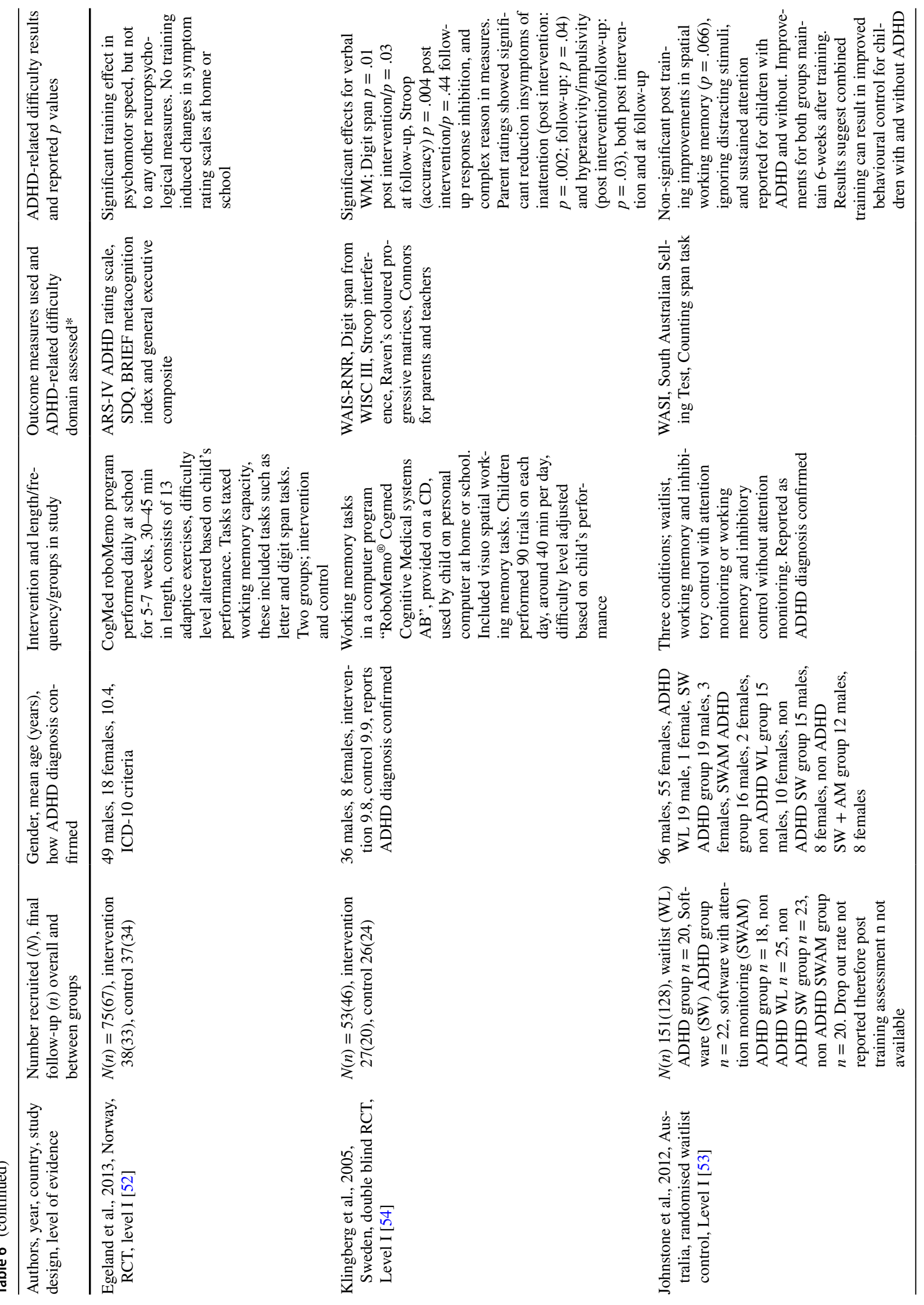


technological interventions that were not for independent use [68-71], two reported on participants who did not have a primary diagnosis of ADHD [72, 73] and two of the studies did not report including participants who had an official clinical diagnosis of ADHD [74, 75]. One of these papers reported participants who had a parent-reported ADHD diagnosis [75]. Papers included in this review all report on participants who have obtained a formal ADHD diagnosis. This is crucial to ensure that comparisons can be made across studies. Parent-reported diagnoses may not be as reliable as clinically reported diagnoses and therefore do not enable comparisons to be made and therefore the results from such studies should be interpreted with caution.

The interventions used in ten $[34,51-57,61,62]$ of the fourteen included studies identified statistically significant results for some, not all, primary outcome measures included in this review. Statistically significant improvements included improved ADHD symptoms [54, 56, 57, 61], social skills [34], executive functioning [51, 52, 54, $55,57]$ and educational outcomes [62]. Statistical significance was not observed for the quality of life [55] or selfefficacy [34] measures which interestingly, only featured in two of the included RCTs $[34,55]$. Although a trend towards improved symptoms [58, 61] and executive functioning [63] was observed in three of the included studies [58, 61, 63], no formal statistical analysis was undertaken and the sample sizes were small ranging from one to eight participants. Therefore, these findings should be interpreted with caution.

As described fully in the quality assessment, one of the eight included RCTs were considered to be at overall high risk of bias [34], two were considered as having an unclear rick of bias $[53,57]$ and five were considered as having a low risk of bias $[51,52,54,55,56]$. This does not mean that interventions were not successful in improving ADHDrelated difficulties. A number of conclusions could be drawn from this including the difficulty of blinding participants to an intervention as it is often impossible to conceal which arm participants are randomised to. It is also difficult to stop a potentially impulsive and hyperactive population to withhold their randomization allocation to an outcome measure assessor. Overall, the included non-RCTs obtained low scores on the Downs and Black scale. Out of a maximum score of 32, two studies scored eleven [59,60], three scored nine [61-63] and one obtained a score of six [58]. A number of conclusions could be drawn from this including low sample sizes and the non-RCT nature of the studies (thus obtaining low scores on items that assess whether or not participants and research staff are blinded).

Of the fourteen included studies in this review, five [34, $52,53,56,57]$ aggregated data with ordinal scales, four used no formal statistical analysis [58-60,63] and two carried out statistical analysis when their sample sizes only consisted of two participants each $[61,62]$. Clinimetric properties were not described for any of the primary outcome measures of this review. The lack of statistical significance across a number of outcome measures in this review could be a result of lack of statistical power due to small sample sizes and the inability to ascertain a clinically meaningful result.

The results from this systematic review should be generalised to a wider population of children and YP with ADHD with caution due to the low recruitment figures for five of included studies where $\mathrm{n}$ ranged from one to twelve [58-62] and only two of the included RCTs had a sample size of more than one hundred [34, 53]. Observations of the lack statistical significance should also be interpreted with caution, given the level of evidence provided and the methodological quality of the existing evidence base.

This review included a small number of papers including 1040 participants overall with 170 being from one study alone [34]. Six of the selected studies recruited fewer than 20 participants [51, 58, 61-63]. This could be for a number of reasons. It may have been difficult to engage with and recruit YP with ADHD to a research study, although this has not been our personal experience.

Additionally, ADHD severity and the presence of comorbidity can affect the level of impairment experienced by the individual, which can affect the way in which they respond to interventions. The included studies did not report the severity of the ADHD in their participants. However, one study [52] reported that their participants were participants were diagnosed with hyperkinetic disorder according to the International Statistical Classification of Diseases and Related Health Problems 10 (ICD-10) [76]. This diagnosis would have been based on narrower criteria than the DSV-IV as in the ICD-10 ADHD is diagnosed based on a minimum number of symptoms in all three dimensions (inattention, impulsivity and hyperactivity) [76] whereas the DSM-IV requires a minimum number of symptoms in one dimension [77]. This means that it is difficult to inter a significant improvement of ADHD-related difficulties.

There are a number of reasons evaluating a complex intervention with this population could remain challenging. For example, no ADHD diagnosis is the same. ADHD is a highly comorbid condition with a large number of potentialrelated difficulties. The extent to which each individual is impaired by their ADHD symptoms and related difficulties are also highly variable. In this review, four studies excluded participants who had specific comorbid diagnosis [51-53, 55]; one study excluded participants with autism spectrum disorder and conduct disorder [55], one study excluded participants diagnosed with pervasive developmental disorders, Tourette's disorder and those who show evidence of bipolar disorder and conduct disorder [52]. One study excluded those diagnosed with pervasive developmental disorder [51] and another study excluded those with any "clinically significant comorbid condition" [53]. These findings should 
be interpreted with caution as at least $65 \%$ of children and YP diagnosed with ADHD have a comorbid condition [1] therefore these participant groups are not representative of the wider ADHD population. These factors coupled with evaluating an intervention make it very difficult to ascertain a clinically significant improvement in this population following the use of an investigative intervention. It also means that it is difficult to control each arm of an RCT study design. It has therefore been suggested [78] that the integration of realist evaluation within an RCT design may be more appropriate for evidence-based medicine whereby "statistically significant benefits may be marginal in clinical practice" [79].

The results of the included studies were not combined for a meta-analysis due to the variety of the types and quality of data collected for the primary outcome measures. It would also be difficult to compare primary outcomes across the included studies accurately as there was a wide variety of measures assessing ADHD-related difficulties used, many of which lacked validity as a measure of ADHD-related difficulties in children and YP.

Despite the wide variety of outcome measures included in this review, none of them assessed ADHD knowledge and understanding. To self-manage ADHD, the Chronic Illness Model [80] states that psychoeducation with a collaborative care model enhances health outcomes [64]. Similarly, the Health Belief Model states that people are more likely to seek treatment if they have knowledge and understanding of their condition [81, 82]. It is important that ADHD psychoeducation delivery is conveyed to the individual and their parents in a culturally appropriate manner, via a reputable website and written and updated by reputable experts [64]. It has been suggested that psychoeducaiton for parents and the YP with ADHD is the first step to treatment [23]. A systematic review has emphasised the value of psychoeducation for children and YP with ADHD can lead to an expert understanding of their condition and lead them to making more positive individual choices [20]. Public Heath England [19] and the Mental Health Taskforce's Five Year Forward View for Mental Health [22] states that early intervention avoids YP falling into crisis and expensive and longer-term interventions into adulthood. Therefore, it is vital that ADHD psychoeducation begins as early as possible following an ADHD diagnosis so that the YP can learn to accept and self-manage their condition in preparation for transition into adulthood.

Transition periods are particularly challenging for somebody diagnosed with ADHD and they present frequently throughout the course of a young person's life. For example YP move to secondary education, undertake regular exams, have to navigate through puberty, sometimes move house and many transfer adult ADHD services. The latter is particularly challenging due to the nature of child and adult ADHD services being very different and providing support in very different ways. Child services provide more in person support and may involve more frequent appointments than adult services. Therefore, a smooth transition between services is vital for a YP with ADHD to minimise disruption [83]. Despite this evidence, none of the included studies provided psychoeducation as part of their interventions.

Future research should focus on the development and cocollaboration of an evidence-based intervention that may focus on psychoeducation for this population. Due to the majority of the included interventions in this review taking the form of computer games, perhaps an ADHD technological intervention with a psychoeducation focus should take a different form such as a website. Evidence suggests that to engage with this population, technological interventions should be interactive $[84,85]$. Research in this area should also consider larger sample sizes and ADHD severity and the presence of comorbid conditions should be reported for participants and accounted for during analysis.

Outcome measures for all interventions for ADHD need to be carefully planned. They should include core symptoms but it is likely that these are not the realistic targets of this type of intervention and goal-orientated outcomes agreed with YP and families may be more relevant. Functional and quality of life outcomes need longer follow-up but in a chronic disorder have far more significance. Finally, advancements in technology and improvements of the suitability of interventions specifically designed for independent use to facilitate self-management could involve a psychoeducational component. Such technologies should be co-designed with stakeholders including children and YP with ADHD adopting a user-centred design methodology to ensure the technology is suitable for this population.

Acknowledgements In collaboration with Sheffield Children's NHS Foundation Trust, this research was funded/supported by the University of Sheffield's School of Health and Related Research (ScHARR) Research Stimulation Prize and the National Institute for Health Research Collaboration for Leadership in Applied Health Research and Care Yorkshire and Humber (NIHR CLAHRC YH). The views and opinions expressed are those of the authors and are not necessarily those of the National Health Service, the National Institute for Health Research, or the UK's Department of Health (DoH).

\section{Compliance with ethical standards}

Conflict of interest The authors declare that thay have no competing interest.

Open Access This article is distributed under the terms of the Creative Commons Attribution 4.0 International License (http://creativecommons.org/licenses/by/4.0/), which permits unrestricted use, distribution, and reproduction in any medium, provided you give appropriate credit to the original author(s) and the source, provide a link to the Creative Commons license, and indicate if changes were made. 


\section{Appendices}

\section{Appendix 1: Medline search strategy}

Database: Ovid MEDLINE(R) Epub Ahead of Print, In-Process \& Other Non-Indexed Citations, Ovid MEDLINE(R) Daily and Ovid MEDLINE(R) $<1946$ to Present $>$. Search Strategy:

1. 1 (Attention Deficit and Disruptive Behaviour Disorders).mp. [mp = title, abstract, original title, name of substance word, subject heading word, keyword heading word, protocol supplementary concept word, rare disease supplementary concept word, unique identifier, synonyms] (2794)

2. 2 Attention Deficit.mp. and Disruptive Behaviour Disorders.tw. [mp $=$ title, abstract, original title, name of substance word, subject heading word, keyword heading word, protocol supplementary concept word, rare disease supplementary concept word, unique identifier, synonyms] (458)

3. 3 Attention deficit hyperactivity disorder.mp. or exp Attention Deficit Disorder with Hyperactivity/(30903)

4. 4 Attention deficit hyperactivity disorder.tw. (19871)

5. 5 exp Attention Deficit Disorder with Hyperactivity/or ADHD.mp. (30310)

6. 6 ADHD.tw. (19992)

7. ADDH.mp. or exp Attention Deficit Disorder with Hyperactivity/(24810)

8. ADDH.tw. (116)

9. ADHS.mp. (613)

10. ADHS.tw. (480)

11. exp Attention Deficit Disorder with Hyperactivity/or exp Hyperkinesis/or hkd.mp. (28643)

12. hkd.tw. (127)

13. exp "Attention Deficit and Disruptive Behaviour Disorders"/or Attention\$.mp. or exp Attention Deficit Disorder with Hyperactivity/(376528)

14. Attention\$.tw. (331436)

15. behav\$.mp. (1423228)

16. behav\$.tw. (1039159)

17. dysfunc\$.mp. (398233)

18. dysfunc\$.tw. (355413)

19. exp Conduct Disorder/or exp Attention Deficit Disorder with Hyperactivity/or disorder\$.mp. (1738736)

20. disorder\$.tw. (923795)

21. disrupt\$.mp. (242609)

22. disrupt\$.tw. (236939)

23. defian\$.mp. (2455)

24. defian\$.tw. (2416)

25. impulsiv\$.mp. (18368)

26. impulsiv\$.tw. (16423)
27. exp Child Behaviour Disorders/or exp Attention Deficit Disorder with Hyperactivity/or inattentive.mp. (43637)

28. inattentiv\$.tw. (2071)

29. exp Child Behaviour Disorders/or exp Attention Deficit Disorder with Hyperactivity/or inattention\$.mp. (45482)

30. inattention\$.tw. (4321)

31. hyperkinesis.mp. or exp Hyperkinesis/(4586)

32. hyperkin\$.tw. (4500)

33. dysfunct $\$$.mp. (398217)

34. dysfunct\$.tw. (355398)

35. damage\$.mp. (524409)

36. damage\$.tw. (495785)

37. hyperactiv\$.mp. or exp Attention Deficit Disorder with Hyperactivity/(57437)

38. hyperactiv\$.tw. (48767)

39. exp "Disruptive, Impulse Control, and Conduct Disorders"/or exp Conduct Disorder/or conduct.mp. (67635)

40. conduct.tw. (59088)

41. 1 or 2 or 3 or 4 or 5 or 6 or 7 or 8 or 9 or 10 or 11 or 12 or 13 or 14 or 15 or 16 or 17 or 18 or 19 or 20 or 21 or 22 or 23 or 24 or 25 or 26 or 27 or 28 or 29 or 30 or 31 or 32 or 33 or 34 or 35 or 36 or 37 or 38 or 39 or 40 (4116307)

42. limit 41 to (english language and humans) (2415834)

43. Child\$.mp. (2191440)

44. Child\$.tw. (1200130)

45. boy \$.mp. (135421)

46. boy\$.tw. (135106)

47. girl\$.mp. (130008)

48. girl\$.tw. (129971)

49. exp Adolescent/or exp Young Adult/or young person. mp. (2105981)

50. young person.tw. (839)

51. YP.mp. (961)

52. YP.tw. (961)

53. exp Adolescent/or exp Young Adult/or young people. mp. (2113601)

54. young people.tw. (21467)

55. exp Adolescent/or adolescen\$.mp. (1892494)

56. adolescen $\$ . t w . ~(226356)$

57. teen\$.mp. or exp Adolescent/(1840488)

58. teen\$.tw. (26444)

59. youth\$.mp. or exp Adolescent/(1855352)

60. youth\$.tw. (57447)

61. 43 or 44 or 45 or 46 or 47 or 48 or 49 or 50 or 51 or 52 or 53 or 54 or 55 or 56 or 57 or 58 or 59 or 60 (3468618)

62. limit 61 to (english language and humans) (2625897)

63. exp Educational Technology/or Technology.mp. or exp Technology/(604158)

64. Technology.tw. (237611) 
65. Assistive technology.mp. or exp Self-Help Devices/ (10593)

66. Assistive technology.tw. (1210)

67. Self-help device\$.mp. or exp Self-Help Devices/(9985)

68. Self-help device\$.tw. (62)

69. exp Video Games/or game\$.mp. (49816)

70. game\$.tw. (45755)

71. exp Internet/or website\$.mp. or exp Software/(196415)

72. website\$.tw. (18842)

73. exp Internet/or exp Software/or download\$.mp. (189332)

74. download\$.tw. (9567)

75. exp Social Media/or exp Internet/or forum\$.mp. (76225)

76. forum\$.tw. (12505)

77. email\$.mp. (5188)

78. email.tw. (4099)

79. mobile app\$.mp. or exp Mobile Applications/(3202)

80. mobile app\$.tw. (1452)

81. 63 or 64 or 65 or 66 or 67 or 68 or 69 or 70 or 71 or 72 or 73 or 74 or 75 or 76 or 77 or 78 or 79 or $80(843422)$

82. limit 81 to (english language and humans) (436105)

83. condition manag\$.mp. (299)

84. condition manag\$.tw. (296)

85. exp Self Care/or manag\$.mp. (1264334)

86. manag\$.tw. (1082943)

87. self-manag\$.mp. or exp Self Care/(56314)

88. self-manag\$.tw. (13985)

89. support.mp. or exp Social Support/(8752243)

90. support.tw. (807612)

91. exp Social Support/or support network\$.mp. (63451)

92. [limit 93 to (english language and humans)] (0)

93. [limit 95 to last 5 years] $(0)$

\section{Appendix 2: References and reasons for exclusion}

\begin{tabular}{ll}
\hline References & Reason for exclusion \\
\hline Barnett et al. [86] & Participants are teachers \\
Benyakorn et al. [87] & Not interventional \\
Bishop [88] & Intervention not technology \\
Bonarini et al[89] & Population focus not ADHD \\
Bul et al. [90] & Outcome measures do not assess \\
& ADHD-related difficulties \\
Chan et al. [91] & Not interventional \\
Chen et al. [92] & Not interventional \\
Christiansen et al. [93] & Intervention reliant on others \\
Dale and Grut [94] & Not exclusively for ADHD \\
Duffy [95] & Population focus not ADHD \\
Enebrink et al. [96] & Population focus not ADHD \\
\hline
\end{tabular}

\begin{tabular}{|c|c|}
\hline References & Reason for exclusion \\
\hline Epstein et al. [97] & $\begin{array}{l}\text { Intervention reliant on health care } \\
\text { professionals }\end{array}$ \\
\hline Fiellin et al. [98] & Population focus not ADHD \\
\hline Frutos-Pascual et al. [99] & Population focus not ADHD \\
\hline $\begin{array}{l}\text { Frutos-Pascual and Garcia- } \\
\text { Zapirain [100] }\end{array}$ & $\begin{array}{l}\text { Participants typically developing, } \\
\text { not ADHD }\end{array}$ \\
\hline Gray et al. [72] & $\begin{array}{l}\text { ADHD not primary diagnosis of } \\
\text { participants }\end{array}$ \\
\hline Halperin et al. [101] & Intervention not technology \\
\hline Janeslätt et al. [102] & Intervention not technology \\
\hline Kim et al. [103] & Intervention not technology \\
\hline Lim et al. [104] & $\begin{array}{l}\text { Intervention reliant on health care } \\
\text { professionals }\end{array}$ \\
\hline Mazurek and Engelhardt [105] & Not interventional \\
\hline Myers et al. [106] & $\begin{array}{l}\text { Participants ADHD diagnosis not } \\
\text { confirmed }\end{array}$ \\
\hline Nie et al. [107] & Intervention not technology \\
\hline Pandria et al. [108] & Not interventional \\
\hline Rohani et al. [109] & $\begin{array}{l}\text { Participants ADHD diagnosis not } \\
\text { confirmed }\end{array}$ \\
\hline Rosch and Mostofsky [110] & Not interventional \\
\hline Schafer et al. [111] & $\begin{array}{l}\text { Participants not received ADHD } \\
\text { diagnosis }\end{array}$ \\
\hline Schuck et al. [112] & $\begin{array}{l}\text { Participants not received ADHD } \\
\text { diagnosis }\end{array}$ \\
\hline Shah et al. 2012 & Not interventional \\
\hline Silva et al. [113] & $\begin{array}{l}\text { Technology as outcome measure, } \\
\text { not intervention }\end{array}$ \\
\hline Steeger et al. 2016 & $\begin{array}{l}\text { Participants ADHD diagnosis not } \\
\text { confirmed }\end{array}$ \\
\hline Stephenson [114] & Population focus not ADHD \\
\hline Tse et al. [115] & $\begin{array}{l}\text { Intervention reliant on health care } \\
\text { professionals }\end{array}$ \\
\hline Vander et al. [116] & $\begin{array}{l}\text { Intervention reliant on health care } \\
\text { professionals }\end{array}$ \\
\hline Wallace et al. [117] & Not interventional \\
\hline Wehmeier et al. [118] & $\begin{array}{l}\text { Intervention reliant on health care } \\
\text { professionals }\end{array}$ \\
\hline Wehmeier et al. [119] & $\begin{array}{l}\text { Intervention reliant on health care } \\
\text { professionals }\end{array}$ \\
\hline Weinstein and Weizman [120] & Review \\
\hline Wronska et al. [121] & $\begin{array}{l}\text { Participants typically developing, } \\
\text { not ADHD }\end{array}$ \\
\hline Wronska et al. [122] & $\begin{array}{l}\text { Participants not received ADHD } \\
\text { diagnosis }\end{array}$ \\
\hline
\end{tabular}

\section{Appendix 3: Details of Cochrane Risk of Bias quality assessment for included RCTs}

Across the included RCTs three reported that the randomisation sequence was computer generated [34, 56, 57] and one reported minimization randomization [55]. These four 


\begin{tabular}{|c|c|c|c|c|c|c|}
\hline Study & $\begin{array}{l}\text { Random } \\
\text { Sequence } \\
\text { Generation } \\
\end{array}$ & $\begin{array}{l}\text { Allocation } \\
\text { Concealment }\end{array}$ & $\begin{array}{l}\text { Blinding of } \\
\text { Participants } \\
\text { and } \\
\text { Personnel } \\
\end{array}$ & $\begin{array}{l}\text { Blinding of } \\
\text { Outcome } \\
\text { Assessment }\end{array}$ & $\begin{array}{l}\text { Incomplete } \\
\text { Outcome } \\
\text { Data } \\
\end{array}$ & $\begin{array}{l}\text { Selective } \\
\text { Reporting }\end{array}$ \\
\hline Bul, 2016 [34] & $\begin{array}{l}\text { Low risk - } \\
\text { computer } \\
\text { program } \\
\text { generated }\end{array}$ & $\begin{array}{l}\text { Low risk - email } \\
\text { allocation }\end{array}$ & $\begin{array}{l}\text { High Risk - } \\
\text { likely blinding } \\
\text { could be } \\
\text { broken }\end{array}$ & $\begin{array}{l}\text { High risk - } \\
\text { blinding could } \\
\text { be broken }\end{array}$ & $\begin{array}{l}\text { High risk - } \\
20 / 88(22 \%) \\
\text { in group one } \\
\text { and } 11 / 82 \\
(13 \%) \text { in } \\
\text { group two } \\
\text { reported as } \\
\text { lost to follow- } \\
\text { up. Analysed } \\
\text { as ITT }\end{array}$ & $\begin{array}{l}\text { Low risk - no } \\
\text { protocol } \\
\text { reported, but } \\
\text { both primary } \\
\text { and secondary } \\
\text { outcomes } \\
\text { assessed and } \\
\text { results } \\
\text { presented }\end{array}$ \\
\hline $\begin{array}{l}\text { Van der Oord, } 2014 \\
\text { [57] }\end{array}$ & $\begin{array}{l}\text { Low risk - } \\
\text { computer } \\
\text { program } \\
\text { generated }\end{array}$ & $\begin{array}{l}\text { Unclear - } \\
\text { allocation } \\
\text { reported as } \\
\text { concealed but } \\
\text { method not } \\
\text { reported }\end{array}$ & $\begin{array}{l}\text { Unclear - } \\
\text { blinding of } \\
\text { participants } \\
\text { and personnel } \\
\text { not reported }\end{array}$ & $\begin{array}{l}\text { Unclear - } \\
\text { blinding of } \\
\text { outcome } \\
\text { assessment not } \\
\text { reported }\end{array}$ & $\begin{array}{l}\text { Low risk - } \\
3 / 21(<20 \%) \\
\text { in } \\
\text { experimental } \\
\text { condition were } \\
\text { non compliant } \\
\text { with the } \\
\text { intervention, } \\
\text { not analysed } \\
\text { as ITT }\end{array}$ & $\begin{array}{l}\text { Low risk - no } \\
\text { protocol } \\
\text { reported, but } \\
\text { both primary } \\
\text { and secondary } \\
\text { outcomes } \\
\text { assessed and } \\
\text { results } \\
\text { presented }\end{array}$ \\
\hline Dovis, 2015 [55] & $\begin{array}{l}\text { Low risk - } \\
\text { minimisation } \\
\text { randomisation } \\
\text { reported }\end{array}$ & $\begin{array}{l}\text { Low risk - done } \\
\text { by a person not } \\
\text { involved in } \\
\text { patient } \\
\text { recruitment }\end{array}$ & $\begin{array}{l}\text { Low risk - } \\
\text { reported as } \\
\text { double blind } \\
\text { RCT }\end{array}$ & $\begin{array}{l}\text { Low risk - } \\
\text { reported as } \\
\text { assessors } \\
\text { blinded }\end{array}$ & $\begin{array}{l}\text { Low risk - } \mathrm{n} \\
\text { lost from each } \\
\text { group }<20 \% \text {. } \\
\text { Analysis by } \\
\text { ITT }\end{array}$ & $\begin{array}{l}\begin{array}{l}\text { Low risk - } \\
\text { reports a } \\
\text { study protocol }\end{array} \\
\end{array}$ \\
\hline $\begin{array}{l}\text { Weerdemeester, } 2016 \\
{[56]}\end{array}$ & $\begin{array}{l}\text { Low risk - } \\
\text { computer } \\
\text { program } \\
\text { generated }\end{array}$ & $\begin{array}{l}\text { Low risk - web- } \\
\text { based allocation }\end{array}$ & $\begin{array}{l}\text { High risk - } \\
\text { blinding of } \\
\text { participants } \\
\text { not possible } \\
\text { due to nature } \\
\text { of study } \\
\end{array}$ & $\begin{array}{l}\text { Low risk - } \\
\text { blinding } \\
\text { assured }\end{array}$ & $\begin{array}{l}\text { Low risk - } \\
<20 \% \text { attrition } \\
\text { rate. }\end{array}$ & $\begin{array}{l}\text { Low risk - no } \\
\text { protocol } \\
\text { reported, but } \\
\text { both primary } \\
\text { and secondary } \\
\text { outcomes } \\
\text { assessed and } \\
\text { results } \\
\text { presented }\end{array}$ \\
\hline $\begin{array}{l}\text { Van Dongen- } \\
\text { Boomsma, 2014 [51] }\end{array}$ & $\begin{array}{l}\text { Unclear - } \\
\text { reports } \\
\text { stratified for } \\
\text { age and } \\
\text { gender, but } \\
\text { not how } \\
\text { randomisation } \\
\text { was conducted }\end{array}$ & $\begin{array}{l}\text { Low risk - done } \\
\text { by a person not } \\
\text { involved in } \\
\text { patient } \\
\text { recruitment }\end{array}$ & $\begin{array}{l}\text { Low risk - } \\
\text { reported as } \\
\text { triple blind } \\
\text { RCT }\end{array}$ & $\begin{array}{l}\text { Low risk-- } \\
\text { reported as } \\
\text { assessors } \\
\text { blinded }\end{array}$ & $\begin{array}{l}\text { Low risk - } \\
1 / 27(<20 \%) \\
\text { and } 3 / 24 \\
(<20 \%) \\
\text { reported as } \\
\text { lost to follow } \\
\text { up. Analysis } \\
\text { by ITT }\end{array}$ & $\begin{array}{l}\text { Low risk - no } \\
\text { protocol } \\
\text { reported, but } \\
\text { both primary } \\
\text { and secondary } \\
\text { outcomes } \\
\text { assessed and } \\
\text { results } \\
\text { presented }\end{array}$ \\
\hline Egeland, 2013 [52] & $\begin{array}{l}\text { Unclear - } \\
\text { reports } \\
\text { numbers } \\
\text { corresponding } \\
\text { to ID status } \\
\text { were drawn }\end{array}$ & $\begin{array}{l}\text { Low risk - done } \\
\text { by a person not } \\
\text { involved in } \\
\text { patient } \\
\text { recruitment }\end{array}$ & $\begin{array}{l}\text { High risk - } \\
\text { blinding of } \\
\text { participants } \\
\text { not possible } \\
\text { due to nature } \\
\text { of study }\end{array}$ & $\begin{array}{l}\text { High risk - } \\
\text { assessors not } \\
\text { blinded }\end{array}$ & $\begin{array}{l}\text { Low risk - } \\
5 / 38(<20 \%) \\
\text { in intervention } \\
\text { group and } \\
3 / 34(<20 \%) \\
\text { in control } \\
\text { group were } \\
\text { reported as } \\
\text { lost to follow } \\
\text { up. No } \\
\text { mention of } \\
\text { what happens } \\
\text { to missing } \\
\text { data, no } \\
\text { mention of } \\
\text { ITT }\end{array}$ & $\begin{array}{l}\text { Low risk - no } \\
\text { protocol } \\
\text { reported, but } \\
\text { both primary } \\
\text { and secondary } \\
\text { outcomes } \\
\text { assessed and } \\
\text { results } \\
\text { presented }\end{array}$ \\
\hline Klingberg, 2005 [54] & $\begin{array}{l}\text { Unclear- } \\
\text { randomisaiton } \\
\text { in blocks of } 4 \\
\text { based on } \\
\text { blinded list of } \\
\text { numbers } \\
\text { associated } \\
\text { with CDs. } \\
\text { Unclear how } \\
\text { blinded list of } \\
\text { numbers were } \\
\text { generated. }\end{array}$ & $\begin{array}{l}\text { Unclear- } \\
\text { method not } \\
\text { reported }\end{array}$ & $\begin{array}{l}\text { Low risk - } \\
\text { Reported as } \\
\text { double blind }\end{array}$ & $\begin{array}{l}\text { Low risk - } \\
\text { reported as } \\
\text { double blind }\end{array}$ & $\begin{array}{l}\text { High risk - } \\
7 / 27(>20 \%) \\
\text { in intervention } \\
\text { group and } \\
2 / 26(<20 \%) \\
\text { in control } \\
\text { group reported } \\
\text { as lost to } \\
\text { follow up. } \\
\text { Missing data } \\
\text { not included in } \\
\text { final analysis } \\
\text { (not ITT) }\end{array}$ & $\begin{array}{l}\text { Low risk - no } \\
\text { protocol } \\
\text { reported, but } \\
\text { both primary } \\
\text { and secondary } \\
\text { outcomes } \\
\text { assessed and } \\
\text { results } \\
\text { presented }\end{array}$ \\
\hline Johnstone, 2012 [53] & $\begin{array}{l}\text { Unclear - } \\
\text { Sequence } \\
\text { generation not } \\
\text { reported }\end{array}$ & $\begin{array}{l}\text { Unclear- } \\
\text { method not } \\
\text { reported }\end{array}$ & $\begin{array}{l}\text { Unclear - } \\
\text { blinding not } \\
\text { reported }\end{array}$ & $\begin{array}{l}\text { Unclear - } \\
\text { outcome } \\
\text { assessor } \\
\text { blinding not } \\
\text { reported }\end{array}$ & $\begin{array}{l}\text { Unclear-drop } \\
\text { out rate not } \\
\text { reported, } \\
\text { method of } \\
\text { analysis for } \\
\text { missing data } \\
\text { not reported }\end{array}$ & $\begin{array}{l}\text { Low risk - no } \\
\text { protocol } \\
\text { reported, but } \\
\text { both primary } \\
\text { and secondary } \\
\text { outcomes } \\
\text { assessed and } \\
\text { results } \\
\text { presented }\end{array}$ \\
\hline
\end{tabular}


RCT's were therefore judged as low risk of selection bias. Four of the RCTs randomization sequence was reported as unclear risk of bias due to lack of reporting of randomization sequence generation [51-54]. Five RCTs reported that treatment allocation was concealed [34, 51, 52, 55, 56] and were therefore judged at low risk of bias for this domain. Three RCTs were judged as unclear risk [53, 54, 57]. One RCT reported that blinding of participants and personnel could be broken [34] and two reported that blinding of participants and personnel was not possible due to the nature of the studies [52, 56]. These two RCTs were judged as having a high risk of bias for this domain. Two RCTs [53, 57] did not report on participant and personnel blinding and were judged as having an unclear risk of bias. Two RCTs were reported as double blind $[54,55]$ and one as triple blind (van boom) and were therefore judged as low risk for this domain. One RCT reported that blinding of the outcome assessor could be broken [34] and one RCT [52] reported that their outcome assessors were not blinded. These two RCTs were judged as having a high risk of bias. Two RCTs $[53,57]$ did not report on binding of their outcome assessor and were therefore judged as having an unclear risk of bias. Four of the included RCTs assured their outcome assessor was blinded and where therefore judged as having a low risk of bias for this domain. Two RCTs [34, 54] had a drop out rate of more than $20 \%$ and one RCT [54] did not include missing data in the final analysis. These two RCTs were therefore judged as having a high risk of bias for the incomplete outcome data domain. One RCT [53] was judged as unclear for this domain as their drop out rate and analysis method of missing data was not reported. The five remaining RCTs [51, 52, 55-57] were judged as having a low risk of bias for this domain as they all had less than a 20\% drop out rate, and two of these conducted an ITT analysis [51, 55]. All eight of the included RCTs were judged as having a low risk of bias for the selective reporting domain. One of these reported a study protocol [55] and the remaining seven did not report a study protocol but did report on all of primary and secondary outcome measures [34, 51-54, 56, 57].

\section{Appendix 4: Details of quality assessment for non-RCT studies}

Three of the six included non-RCT studies presented clear aims and objectives [59, 60,62]. All six studies described their outcome measures and their participants appropriately [58-63]. Four studies clearly described the intervention [59-61, 63]. None of the studies described confounding variables. Five studies clearly described their findings [59-63] and one study partially described their findings [58]. Accounting for participant loss to follow-up was not applicable to all six studies as participants did not drop out of these studies [58-63]. Four of the studies did not report probability values as no formal statistical analysis were performed $[58-60,63]$. The statistical tests that were used in two of the studies [61,62] were judged as inappropriate due to low sample sizes of two participants recruited to each of the studies [61, 62]. Overall, scores were low for external validity. None of the studies approached or recruited people who were representative of their target population (ref all), three of the studies involved individuals who are representative of the treatment the population would usually receive $[59,60,63]$ and this was unclear to determine in three of the studies [58, 61, 62]. Overall, scores for internal validity were also low. No studies blinded participants or those who collected data, perhaps due to their non-RCT study designs. One study did not involve a follow-up data collection period [58], four studies had appropriate follow-up periods [59, 60, $62,63]$, and one study did not have an appropriate amount of time between initial data collection and follow-up to determine an effect of their intervention [61]. Compliance with the intervention was reliable in four of the six studies [58-61] and unclear to determine in two of the studies [62, 63]. Two of the six studies used validated outcome measures $[58,63]$ and the other four studies did not [59-62]. Overall, the studies obtained low scores for the selection bias items of this scale. Two of the selected studies $[59,60]$ recruited all of their participants from the same population. This was unclear to determine in two of the studies [61, 62], inapplicable to one case study [58] and not the case for one study [63]. All studies recruited their study participants over the same period of time [58-63]. None of these studies used randomization for group allocation where applicable, as they are not RCTs and did not report adjusting any analyses for any confounding variables [58-63]. Due to low sample sizes, all six of the included non-RCT studies have been judged to not have sufficient power to detect a clinically important effect.

\section{Appendix 5: Summary of outcome measurement quality assessment}




\begin{tabular}{ll}
\hline $\begin{array}{l}\text { Authors, year, country, study } \\
\text { design }\end{array}$ & $\begin{array}{l}\text { Measures of ADHD-related dif- } \\
\text { ficulties }\end{array}$
\end{tabular}

TMQ_- parent and teacher completion, subscale Plan/Organise and working memory of BRIEF, Subscale of cooperation, responsibiity, assertiveness, self control and total SRRS of SRRS, IATQ, SRRS teacher version, self efficacy questionnaire

Van der Oord, 2014, The Netherlands, 2 arm RCT [van der Oord, 2014 \#1330]

Dovis, 2015, The Netherlands, 4 arm double blind RCT [Dovis, 2015 \#6591]

Bamford, 2016, USA, Single subject design (ABAB) [Bamford, 2016 \#8050]

Pinna, 2015, USA, Case series [Pinna, 2015 \#8049]

Ruiz-Manrique, 2016, Spain, Case stud [Ruiz-Manrique, 2014 \#8048]

Weerdemeester, 2016, The Netherlands, Feasibility RCT [Weerdmeester, 2016 \#8046]

Shih, 2014, Taiwan, Before and after case series [Shih, 2014 \#969]

Lin, 2016, Taiwan, Single case ABA design [62]

Rijo, 2015, Portugal, Before and after case series [63]

Van Dongen-Boomsma, 2014, The Netherlands, randomised placebo control trial [51]

Egeland, 2013, Norway, RCT [52]

Klingberg, 2005, Sweden, double blind RCT [52]

Johnstone, 2012, Australia, randomised waitlist control [53]
BRIEF DBDRS DBDRS

Improvement index during training, Stop task Stroop, CBTT, WISC-III, TMT of D-KFES, Raven, DBDRS, BRIEF, SPRSQ-C, PedsQL, HSQ

Guided reading packet, multiple choice

Total time to complete reading, calculating time for distractions, time calculation

Conners parent Scale (brief version), Connors teacher rating scale, BSSQ, Conners CPT

AVL, Go/no-go task, MABC2-NL

Action detector and duration of arbitrary standing

Three subtests in Mandarin Literacy Assessment

\section{CPT II, WISC III}

ADHD-RS, BRIEF, Adapted digit span from WISC-III, Knox Cubes LDT, Sentences WPPSIRN, Shortened Ravens Progressive Matrices, Day night stroop task, Sustained attention dots task version $02 \mathrm{k}$, Shape school

\section{ADHD-RS, SDQ, BRIEF meta-} cognition index,

WAIS-RNI, digit span from WISC-III, Stroop interference, Ravens coloured progressive matrices, Connors (parent and teacher versions)

WASI, SAST, counting span task

Stop task, Stroop, CBTT, WISC-III, BRIEF, SPRSQ-C, PedsQL

Conners parent and teacher BSSQ scales, Conners CPT

AVL, MABC-2-NL
Outcome measures where psychometric properties assessed

$\begin{array}{ll}\text { BRIEF, SRRS TMQ, IATQ } & \begin{array}{c}\text { Aggregated data used with } \\ \text { ordinal scales }\end{array}\end{array}$

Outcome measures properties not assessed where psychometric

Analysis method appropriate

Improvement index during training,

D-KFES, Raven, DBDRS, HSQ

Guided reading packet, multiple choice

Total time to complete reading, calculating time for distractions time calculation

Go/no-go task
Action detector and duration of arbitrary standing

Three subtests in Mandarin Literacy Assessment

CPT II, WISC III

ADHD-RS, BRIEF, WISC III, stroop task, Knox cubes LDT, WPPSI-RN

ADHD-RS, SDQ, BRIEF -

WISC III, Connors, WAIS- Ravens progressive RNI, Stroop interference colour matricies

SAST, WASI
Shortened Ravens sustained attention dots task version $02 \mathrm{k}$, shape school

Counting span task progressive matrices,
No formal statistical analysis presented, small sample size $(n=4)$

No formal stats presented, small sample size $(n=9)$

Aggregated data used with ordinal scales (BRIEF, DBDRS)

Yes$$
\text { small sample size }(n=9)
$$

No formal stats presented, small sample size $(n=1)$, Conners CPT scores not presented

Aggregated data used with ordinal scale for AVL should be interpreted with caution due to low sample size $(n=2)$

No. Statistical significance should be interpreted with caution due to low sample size $(n=2)$

No formal stats presented, small sample sizes of ( $n=4$ and $n=12$ )

Yes
No. Statistical significance
Aggregated data used with ordinal scale for SDQ

Yes
Aggregated data used with
ordinal scales 


\section{References}

1. Biederman J, Newcorn J, Sprich S (1991) Comorbidity of attention deficit hyperactivity disorder. Am J Psychiatry 148(5):564-577

2. Kadesjö B, Gillberg C (2001) The comorbidity of ADHD in the general population of Swedish school-age children. J Child Psychol Psychiatry 42(4):487-492

3. Yoshimasu K et al (2012) Childhood ADHD is strongly associated with a broad range of psychiatric disorders during adolescence: a population-based birth cohort study. J Child Psychol Psychiatry 53(10):1036-1043

4. Polanczyk G et al (2007) The worldwide prevalence of ADHD: a systematic review and metaregression analysis. Am J Psychiatry 164(6):942-948

5. Barkley RA et al (1990) The adolescent outcome of hyperactive children diagnosed by research criteria: I. An 8-year prospective follow-up study. J Am Acad Child Adolesc Psychiatry 29(4):546-557

6. Biederman J et al (1996) Predictors of persistence and remission of ADHD into adolescence: results from a four-year prospective follow-up study. J Am Acad Child Adolesc Psychiatry 35(3):343-351

7. Gittelman R et al (1985) Hyperactive boys almost grown up: I. Psychiatric status. Arch Gen Psychiatry 42(10):937-947

8. Weiss G et al (1985) Psychiatric status of hyperactives as adults: a controlled prospective 15-year follow-up of 63 hyperactive children. J Am Acad Child Psychiatry 24(2):211-220

9. Faraone SV, Biederman J, Mick E (2006) The age-dependent decline of attention deficit hyperactivity disorder: a meta-analysis of follow-up studies. Psychol Med 36(02):159-165

10. Harpin VA (2005) The effect of ADHD on the life of an individual, their family, and community from preschool to adult life. Arch Dis Child 90(suppl 1):i2-i7

11. Mannuzza S, Klein RG (2000) Long-term prognosis in attentiondeficit/hyperactivity disorder. Child and adolescent psychiatric clinics of North America

12. Kuriyan AB et al (2013) Young adult educational and vocational outcomes of children diagnosed with ADHD. J Abnorm Child Psychol 41(1):27-41

13. Barkley RA (1997) Behavioral inhibition, sustained attention, and executive functions: constructing a unifying theory of ADHD. Psychol Bull 121(1):65

14. Johnston C, Mash EJ (2001) Families of children with attentiondeficit/hyperactivity disorder: review and recommendations for future research. Clin Child Fam Psychol Rev 4(3):183-207

15. de Boo GM, Prins PJ (2007) Social incompetence in children with ADHD: possible moderators and mediators in social-skills training. Clin Psychol Rev 27(1):78-97

16. Klassen AF, Miller A, Fine S (2004) Health-related quality of life in children and adolescents who have a diagnosis of attentiondeficit/hyperactivity disorder. Pediatrics 114(5):e541-e547

17. Peasgood T et al (2016) The impact of ADHD on the health and well-being of ADHD children and their siblings. Eur Child Adolesc Psychiatry 25(11):1217-1231

18. Young S, Murphy CM, Coghill D (2011) Avoiding the "twilight zone': recommendations for the transition of services from adolescence to adulthood for young people with ADHD. BMC Psychiatry 11(1):174

19. Public Health England (2016) The mental health of children and young people in England. https://www.gov.uk/government/ uploads/system/uploads/attachment_data/file/575632/Mental_ health_of_children_in_England.pdf. Cited 30th May 2017

20. Ferrin M, Taylor E (2011) Child and caregiver issues in the treatment of attention deficit-hyperactivity disorder: education, adherence and treatment choice. Fut Neurol 6(3):399-413
21. The Health Foundation (2011) Helping people help themselves. http://www.health.org.uk/sites/health/files/HelpingPeopleHelpThemselves.pdf. Cited 30th May 2017

22. The Mental Health Taskforce (2016) The five year forward view for mental health. https://www.england.nhs.uk/wp-content/ uploads/2016/02/Mental-Health-Taskforce-FYFV-final.pdf. Cited 30th May 2017

23. Taylor E et al (2004) European clinical guidelines for hyperkinetic disorder-first upgrade. Eur Child Adolesc Psychiatry 13(1):i7-i30

24. Internet Live Stats (2016) Number of internet users. http://www. internetlivestats.com/internet-users/. Cited 16th Jan 2017

25. Garcia-Zapirain B, de la Torre Díez I, López-Coronado M (2017) Dual system for enhancing cognitive abilities of children with ADHD using leap motion and eye-tracking technologies. J Med Syst 41(7):111

26. Blandón DZ et al (2016) Influence of a BCI neurofeedback videogame in children with ADHD. Quantifying the brain activity through an EEG signal processing dedicated toolbox. In: Computing Conference (CCC), 2016 IEEE 11th Colombian. IEEE

27. Lim CG et al (2017) Effectiveness of a brain-computer interface based programme for the treatment of ADHD: a pilot study. Psychopharmacol Bull 43(1):73-82

28. Edebol H, Helldin L, Norlander T (2013) Measuring adult attention deficit hyperactivity disorder using the quantified behavior test plus. PsyCh J 2(1):48-62

29. Cortese $S$ et al (2015) Cognitive training for attention-deficit/ hyperactivity disorder: meta-analysis of clinical and neuropsychological outcomes from randomized controlled trials. J Am Acad Child Adolesc Psychiatry 54(3):164-174

30. Shrieber B, Seifert T (2009) College students with learning disabilities and/or ADHD use of a handheld computer compared to conventional planners. In: Proceedings of the chairs conference on instructional technologies research

31. Gulchak DJ (2008) Using a mobile handheld computer to teach a student with an emotional and behavioral disorder to self-monitor attention. Educ Treat Child 31(4):567-581

32. Hecker $L$ et al (2002) Benefits of assistive reading software for students with attention disorders. Ann Dyslexia 52(1):243-272

33. Ota KR, DuPaul GJ (2002) Task engagement and mathematics performance in children with attention-deficit hyperactivity disorder: effects of supplemental computer instruction. Sch Psychol Q 17(3):242

34. Bul KC et al (2016) Behavioral outcome effects of serious gaming as an adjunct to treatment for children with attention-deficit/ hyperactivity disorder: a randomized controlled trial. J Med Internet Res 18(2):e26

35. Moher D et al (2010) Preferred reporting items for systematic reviews and meta-analyses: the PRISMA statement. Int J Surg $8(5): 336-341$

36. Higgins JP, Green S (2011) Cochrane handbook for systematic reviews of interventions, vol 4. Wiley, New York

37. Downs SH, Black N (1998) The feasibility of creating a checklist for the assessment of the methodological quality both of randomised and non-randomised studies of health care interventions. J Epidemiol Community Health 52(6):377-384

38. Roseman F et al (2013) Implementation of the INTERGROWTH21 st project in the UK. BJOG Int J Obstet Gynaecol 120(Suppl 2):117-122

39. Tyson S, Connell L (2009) The psychometric properties and clinical utility of measures of walking and mobility in neurological conditions: a systematic review. Clin Rehabil 23(11):1018-1033

40. Altaim T (2015) Developing a functional outcome measure for individuals with low back pain within a Jordanian physiotherapy service. University of Sheffield 
41. de Vet HC, Terwee CB, Bouter LM (2003) Current challenges in clinimetrics. J Clin Epidemiol 56(12):1137-1141

42. Feinstein AR (1983) An additional basic science for clinical medicine: IV. The development of clinimetrics. Ann Intern Med 99(6):843-848

43. Kirshner B, Guyatt G (1985) A methodological framework for assessing health indices. J Chronic Dis 38(1):27-36

44. Okasheh ROA (2011) Clinical measurement of functional outcomes of pulmonary rehabilitation. Sheffield Hallam University

45. Mawson SJ (1993) Measuring physiotherapy outcome in stroke rehabilitation. Physiotherapy 79(11):762-765

46. Michels E (1983) Measurement in physical therapy. On the rules for assigning numerals to observations. Phys Ther 63(2):209-215

47. Stevens SS (1946) On the theory of scales of measurement. Science 103(2684):677-680

48. Weiss PL et al (2009) Video capture virtual reality: a decade of rehabilitation assessment and intervention. Phys Ther Rev 14(5):307-321

49. Nelson AM (2008) Addressing the threat of evidence-based practice to qualitative inquiry through increasing attention to quality: a discussion paper. Int J Nurs Stud 45(2):316-322

50. Sackett DL et al (2002) Evidence-based medicine: how to practice and teach EBM, 2nd edn. Churchill Livingstone, New York

51. Dongen-Boomsma $M$ et al (2014) Working memory training in young children with ADHD: a randomized placebo-controlled trial. J Child Psychol Psychiatry 55(8):886-896

52. Egeland J, Aarlien AK, Saunes B-K (2013) Few effects of far transfer of working memory training in ADHD: a randomized controlled trial. PLoS One 8(10):e75660

53. Johnstone SJ et al (2012) Neurocognitive training for children with and without AD/HD. ADHD Atten Deficit Hyperact Disord 4(1):11-23

54. Klingberg $\mathrm{T}$ et al (2005) Computerized training of working memory in children with ADHD-a randomized, controlled trial. J Am Acad Child Adolesc Psychiatry 44(2):177-186

55. Dovis $S$ et al (2015) Improving executive functioning in children with ADHD: Training multiple executive functions within the context of a computer game. A randomized double-blind placebo controlled trial. PLoS One 10(4):e0121651

56. Weerdmeester J et al (2016) A feasibility study on the effectiveness of a full-body videogame intervention for decreasing attention deficit hyperactivity disorder symptoms. Games Health J 5(4):258-269

57. van der Oord S et al (2014) A pilot study of the efficacy of a computerized executive functioning remediation training with game elements for children with ADHD in an outpatient setting: outcome on parent- and teacher-rated executive functioning and ADHD behavior. J Attent Disord 18(8):699-712

58. Ruiz-Manrique G, Tajima-Pozo K, Montañes-Rada F (2014) Case report: "ADHD Trainer": the mobile application that enhances cognitive skills in ADHD patients. F1000Research 3

59. Bamford C (2016) The effects of self-monitoring using an iPad to increase on-task behaviors of high school students with Attention Deficit/Hyperactivity Disorder (ADHD). Rowan University

60. Pinna JE (2015) Development and preliminary testing of tablet application to increase reading motivation and summarization for adolescent students with ADHD. University of Baltimore

61. Shih CH, Wang SH, Wang YT (2014) Assisting children with attention deficit hyperactivity disorder to reduce the hyperactive behavior of arbitrary standing in class with a Nintendo Wii remote controller through an active reminder and preferred reward stimulation. Res Dev Disabil 35(9):2069-2076

62. Lin C-Y et al (2016) The effect of literacy learning via mobile augmented reality for the students with ADHD and reading disabilities, in universal access in human-computer interaction: users and context diversity, Pt III. In: Antona M, Stephanidis C (eds.) $103-111$

63. Rijo R et al (2015) Mysterious bones unearthed: development of an online therapeutic serious game for children with attention deficit-hyperactivity disorder. In: CruzCunha MM et al (eds) Conference on Enterprise Information Systems/International Conference on Project Management/Conference on Health and Social Care Information Systems and Technologies, Centeris/ Projman/Hcist. pp 1208-1216

64. Bussing R et al (2012) ADHD knowledge, perceptions, and information sources: perspectives from a community sample of adolescents and their parents. J Adolesc Health 51(6):593-600

65. Tamm L et al (2013) Preliminary data suggesting the efficacy of attention training for school-aged children with ADHD. Dev Cogn Neurosci 4:16-28

66. Tucha $\mathrm{O}$ et al (2011) Training of attention functions in children with attention deficit hyperactivity disorder. ADHD Attent Deficit Hyperact Disord 3(3):271-283

67. Johnstone SJ et al (2010) A pilot study of combined working memory and inhibition training for children with AD/HD. ADHD Attent Deficit Hyperact Disord 2(1):31-42

68. Hovik KT et al (2013) RCT of working memory training in ADHD: long-term near-transfer effects. PLoS One 8(12):e80561

69. Shalev L, Tsal Y, Mevorach C (2007) Computerized progressive attentional training (CPAT) program: effective direct intervention for children with ADHD. Child Neuropsychol 13(4):382-388

70. Steiner NJ et al (2014) Neurofeedback and cognitive attention training for children with attention-deficit hyperactivity disorder in schools. J Dev Behav Pediatr 35(1):18-27

71. Steiner NJ et al (2011) Computer-based attention training in the schools for children with attention deficit/hyperactivity disorder: a preliminary trial. Clin Pediatr 50(7):615-622

72. Gray S et al (2012) Effects of a computerized working memory training program on working memory, attention, and academics in adolescents with severe LD and comorbid ADHD: a randomized controlled trial. J Child Psychol Psychiatry 53(12):1277-1284

73. Green CT et al (2012) Will working memory training generalize to improve off-task behavior in children with attention-deficit/ hyperactivity disorder? Neurotherapeutics 9(3):639-648

74. Chacko A et al (2014) A randomized clinical trial of Cogmed working memory training in school-age children with ADHD: a replication in a diverse sample using a control condition. J Child Psychol Psychiatry 55(3):247-255

75. Rabiner DL et al (2010) A randomized trial of two promising computer-based interventions for students with attention difficulties. J Abnorm Child Psychol 38(1):131-142

76. World Health Organization (2017) The ICD-10 classification of mental and behavioural disorders: clinical descriptions and diagnostic guidelines. http://www.who.int/classifications/icd/en/ bluebook.pdf. Cited 22nd Sep 2017.

77. National Institute for Health and Care Excellence (2017) Attention deficit hyperactivity disorder: the MICE guideline on diagnosis and management of ADHD in children, young people and adults. Cited 22nd Sep 2017.

78. Bonell C et al (2012) Realist randomised controlled trials: a new approach to evaluating complex public health interventions. Soc Sci Med 75(12):2299-2306

79. Greenhalgh T, Howick J, Maskrey N (2014) Evidence based medicine: a movement in crisis? BMJ 348:g3725

80. Subcommittee on Attention deficit hyperactivity disorder steering committee on quality improvement and management: clinical practice guideline for the diagnosis, evaluation, and treatment of attention-deficit/hyperactivity disorder in children and adolescents. Pediatrics, 2011: 2011-2654 
81. Janz NK, Becker MH (1984) The health belief model: a decade later. Health Educ Q 11(1):1-47

82. Rosenstock IM (1974) Historical origins of the health belief model. Health Educ Monogr 2(4):328-335

83. Swift KD et al (2013) Transition to adult mental health services for young people with Attention Deficit/Hyperactivity Disorder (ADHD): a qualitative analysis of their experiences. BMC Psychiatry 13(1):74

84. Powell L, Parker J, Robertson N, Harpin V (2017) Attention deficit hyperactivity disorder: is there an app for that? Suitability assessment of apps for children and young people with ADHD. JMIR Mhealth Uhealth 5(10):e145

85. Powell L, Parker J, Harpin V (2017) ADHD: is there an app for that? A suitability assessment of apps for the parents of children and young people with ADHD. JMIR Mhealth Uhealth 5(10):e149

86. Barnett B, Corkum P, Elik N (2012) A web-based intervention for elementary school teachers of students with attention-deficit/ hyperactivity disorder (ADHD). Psychol Serv 9(2):227-230

87. Benyakorn S et al (2016) Current state and model for development of technology-based care for attention deficit hyperactivity disorder. Telemed E-Health 22(9):761-768

88. Bishop J (2014) Gamification for human factors integration: Social, education, and psychological issues xxiv, 336 pp Hershey. Information Science Reference/IGI Global; US, PA, US, p 2014

89. Bonarini A et al (2016) A huggable, mobile robot for developmental disorder interventions in a multi-modal interaction space. In: 2016 25th IEEE International Symposium on Robot and Human Interactive Communication. p 823-830

90. Bul KCM et al (2015) Development and user satisfaction of "plan-it commander", a serious game for children with ADHD. Games Health J 4(6):502-512

91. Chan S, Parish M, Yellowlees P (2015) Telepsychiatry today. Curr Psychiatry Rep 17(11):89

92. Chen YL, Chen SH, Gau SS (2015) ADHD and autistic traits, family function, parenting style, and social adjustment for Internet addiction among children and adolescents in Taiwan: a longitudinal study. Res Dev Disabil 39:20-31

93. Christiansen $\mathrm{H}$ et al (2014) Slow cortical potential neurofeedback and self-management training in outpatient care for children with ADHD: study protocol and first preliminary results of a randomized controlled trial. Front Hum Neurosci 8:943

94. Dale O, Grut L (2015) Mainstream ICT Can support children and adolescents with ADHD and/or autism in their everyday activities. Stud Health Technol Inform 217:679-684

95. Duffy LV (2013) Testing the efficacy of the creating opportunities for parent empowerment (COPE) intervention during hospital to home transition: empowering parents of children with epilepsy and other neurological conditions. Boston College 204

96. Enebrink P et al (2012) Internet-based parent management training: a randomized controlled study. Behav Res Ther 50(4):240-249

97. Epstein JN et al (2013) The myADHDportal.Com Improvement Program: an innovative quality improvement intervention for improving the quality of ADHD care among communitybased pediatricians. Clinical Practice in Pediatric. Psychology 1(1):55-67

98. Fiellin LE, Hieftje KD, Duncan LR (2014) Videogames, here for good. Pediatrics 134(5):849-851

99. Frutos-Pascual M, Garcia Zapirain B, Mendez Zorrilla A (2014) Adaptive tele-therapies based on serious games for health for people with time-management and organisational problems: preliminary results. Int J Environ Res Public Health 11(1):749-772

100. Frutos-Pascual M, Garcia-Zapirain B (2015) Assessing visual attention using eye tracking sensors in intelligent cognitive therapies based on serious games. Sensors 15(5):11092-11117
101. Halperin JM et al (2013) Training executive, attention, and motor skills: a proof-of-concept study in preschool children With ADHD. J Attent Disord 17(8):711-721

102. Janeslatt G, Kottorp A, Granlund M (2014) Evaluating intervention using time aids in children with disabilities. Scand J Occup Ther 21(3): 181-190

103. Kim J-W, Sharma V, Ryan ND (2015) Predicting methylphenidate response in ADHD using machine learning approaches. Int J Neuropsychopharmacol 18(11):1-7

104. Lim CG et al (2012) A brain-computer interface based attention training program for treating attention deficit hyperactivity disorder. PLoS One 7(10):e46692 [Electronic Resource]

105. Mazurek MO, Engelhardt CR (2013) Video game use in boys with autism spectrum disorder, ADHD, or typical development. Pediatrics 132(2):260-266

106. Myers K, Stoep AV, Lobdell C (2013) Feasibility of conducting a randomized controlled trial of telemental health with children diagnosed with attention-deficit/hyperactivity disorder in underserved communities. J Child Adolesc Psychopharmacol 23(6):372-378

107. Nie J et al (2016) Impaired inhibition and working memory in response to internet-related words among adolescents with internet addiction: a comparison with attention-deficit/hyperactivity disorder. Psychiatry Res 236:28-34

108. Pandria $\mathrm{N}$ et al (2015) The future of mobile health ADHD applications projecting WHAAM application on future mobile health. In: Proceedings of 2015 International Conference on Interactive Mobile Communication Technologies and Learning (Imcl), pp 279-282

109. Rohani DA, Sorensen HB, Puthusserypady S (2014) Brain-computer interface using P300 and virtual reality: a gaming approach for treating ADHD. In: Conference Proceedings Annual International Conference of the IEEE Engineering in Medicine and Biology Society, pp 3606-9

110. Rosch KS, Mostofsky SH (2016) Increased delay discounting on a novel real-time task among girls, but not boys, with ADHD. J Int Neuropsychol Soc 22(1):12-23

111. Schafer EC et al (2014) Use of wireless technology for children with auditory processing disorders, attention-deficit hyperactivity disorder, and language disorders. Semin Hear 35(3):193-205

112. Schuck $S$ et al (2016) Designing an iPad app to monitor and improve classroom behavior for children with ADHD: iSelfControl feasibility and pilot studies. Plos One 11(10):e0164229

113. Silva AP et al (2015) Measurement of the effect of physical exercise on the concentration of individuals with ADHD. PLoS One 10(3):e0122119 [Electronic Resource]

114. Stephenson J (2016) Using the Choiceboard Creator ${ }^{\mathrm{TM}}$ app on an $\mathrm{iPad} \odot$ to teach choice making to a student with severe disabilities. AAC Augment Altern Commun 32(1):49-57

115. Tse YJ et al (2015) Teletherapy delivery of caregiver behavior training for children with attention-deficit hyperactivity disorder. Telemed E-Health 21(6):451-458

116. Stoep AV, Myers K (2013) Methodology for conducting the children's attention-deficit hyperactivity disorder telemental health treatment study in multiple underserved communities. Clin Trials 10(6):949-958

117. Wallace $\mathrm{C}$ et al (2016) Attention-deficit/hyperactivity disorder, behavior regulation and virtual school support. J Dev Behav Pediatr 37(3):254-256

118. Wehmeier PM et al (2012) Does atomoxetine improve executive function, inhibitory control, and hyperactivity? Results from a placebo-controlled trial using quantitative measurement technology. J Clin Psychopharmacol 32(5):653-660

119. Wehmeier PM et al (2014) Does stimulant pretreatment modify atomoxetine effects on core symptoms of ADHD in children 
assessed by quantitative measurement technology? J Attent Disord 18(2):105-116

120. Weinstein A, Weizman A (2012) Emerging association between addictive gaming and attention-deficit/hyperactivity disorder. Curr Psychiatry Rep 14(5):590-597

121. Wronska N, Garcia-Zapirain B, Mendez-Zorrilla A (2015) An iPad-Based tool for improving the skills of children with attention deficit disorder. Int J Environ Res Public Health 12(6):62616280 [Electronic Resource]
122. Wronska N, Garcia-Zapirain B, Mendez-Zorrilla A (2015) An iPad-Based tool for improving the skills of children with attention deficit disorder. Int J Environ Res Public Health 12(6):6261-6280 